Monique lanne Jordão Ferreira

\title{
Planejamento da Manutenção de Sistemas de Distribuição Baseado em Índices de Confiabilidade
}

\author{
Dissertação de Mestrado \\ Dissertação apresentada como requisito parcial para \\ obtenção do grau de Mestre pelo Programa de Pós- \\ Graduação em Engenharia Elétrica da PUC-Rio.
}

Orientador: Prof. Armando Martins Leite da Silva 


\title{
Monique lanne Jordão Ferreira
}

\section{Planejamento da Manutenção de Sistemas de Distribuição Baseado em Índices de Confiabilidade}

\begin{abstract}
Dissertação apresentada como requisito parcial para obtenção do grau de Mestre pelo Programa de Pós-Graduação em Engenharia Elétrica da PUC-Rio. Aprovada pela Comissão Examinadora abaixo assinada.
\end{abstract}

Prof. Armando Martins Leite da Silva

Orientador

Departamento de Engenharia Elétrica - PUC-Rio

Dr. José Filho da Costa Castro Empresa de Pesquisa Energética - EPE

Prof. João Guilherme de Carvalho Costa Universidade Federal de Itajubá - UNIFEI

Rio de Janeiro, 12 de abril de 2019. 
Todos os direitos reservados. É proibida a reprodução total ou parcial do trabalho sem autorização da universidade, do autor

e do orientador.

\section{Monique lanne Jordão Ferreira}

Nasceu em Volta Redonda, Brasil, no ano 1992. Em 2014, graduouse em Engenharia Elétrica na Universidade Severino Sombra. Atualmente trabalha na Concessionária de Energia Elétrica Light S.E.S.A. Suas principais áreas de interesse são o planejamento e confiabilidade de sistemas elétricos de potência.

Ficha Catalográfica

Ferreira, Monique lanne Jordão

Planejamento da manutenção de sistemas de distribuição baseado em índices de confiabilidade / Monique lanne Jordão

Ferreira ; orientador: Armando Martins Leite da Silva - 2019.

85 f. : il. color. ; $30 \mathrm{~cm}$

Dissertação (mestrado)-Pontifícia Universidade Católica do Rio de Janeiro, Departamento de Engenharia Elétrica, 2019.

Inclui bibliografia

1. Engenharia Elétrica - Teses. 2. Confiabilidade. 3. Planejamento da manutenção. 4. Índices de confiabilidade. 5. Matriz de risco. 6. Redes de distribuição. I. Leite da Silva, Armando Martins. II. Pontifícia Universidade Católica do Rio de Janeiro. Departamento de Engenharia Elétrica. III. Título.

CDD: 621.3 


\section{Agradecimentos}

Primeiramente, agradeço a Deus, a essa "força maior" que nos protege e faz com que tudo dê sempre certo.

Ao meu orientador Prof. Armando Martins Leite da Silva por compartilhar seus conhecimentos, pela paciência, orientação e enorme incentivo para concluir este ciclo. Obrigada pelo voto de confiança e toda dedicação.

Aos meus pais e minha irmã, por sonharem junto comigo.

Ao meu primo Pablo Jordão, pelo auxílio na realização deste trabalho.

Ao Romulo Teixeira, por cuidar da minha filha enquanto minha ausência era necessária e por toda a ajuda.

À minha filha, Clarisse Teixeira, pelo amor incondicional.

Aos amigos Eymile Tavares, Riller Marinho e Natasha Monteiro, por estarem sempre ao meu lado.

Aos professores do Departamento de Engenharia Elétrica pela oportunidade e conhecimentos adquiridos.

Finalmente, agradeço à PUC-Rio pelos auxílios concedidos, sem os quais este trabalho não poderia ter sido realizado.

O presente trabalho foi realizado com o apoio da Coordenação de Aperfeiçoamento de Pessoal de Nível Superior - Brasil (CAPES) - Código de Financiamento 001. 


\section{Resumo}

Ferreira, Monique Ianne Jordão; Leite da Silva, Armando Martins. Planejamento da Manutenção de Sistemas de Distribuição Baseado em Índices de Confiabilidade. Rio de Janeiro, 2019. 85p. Dissertação de Mestrado - Departamento de Engenharia Elétrica, Pontifícia Universidade Católica do Rio de Janeiro.

No sistema elétrico de potência podem ocorrer falhas que resultarão na interrupção do fornecimento de energia para os consumidores conectados a esses sistemas. Uma concessionária de energia elétrica deve prestar aos seus clientes um serviço que seja confiável e de boa qualidade. Por isso, o planejamento seguro e eficiente se faz necessário para obter a confiabilidade do sistema elétrico de acordo com as exigências estabelecidas pela agência reguladora do setor, onde caso não sejam observadas pela distribuidora de energia são cabíveis de punições monetárias. O desempenho de um sistema pode ser observado com base no histórico de interrupções, por meio dos indicadores de continuidade. A baixa flexibilidade operativa de subestações aliada à configuração das redes reduz a confiabilidade dos sistemas, causando prejuízos às empresas e aos consumidores por estarem vulneráveis e sofrerem interrupções de energia. O presente estudo é essencial, pois visa identificar métodos e análises apuradas que indiquem os pontos prioritários para manutenções nas redes elétricas. Dessa forma, a dissertação apresenta uma metodologia que identifica os equipamentos e trechos associados aos pontos críticos e de maior impacto em uma rede de distribuição. A partir daí é possível direcionar os serviços de manutenção dos circuitos para os trechos de maior impacto nos indicadores de continuidade de uma determinada região e otimizar o orçamento correspondente. A ferramenta usada para analisar os indicadores é uma matriz de risco, onde os eixos representam probabilidade de ocorrência (reincidência) e impacto corporativo (índice de continuidade) de modo a capturar mais precisamente os pontos para atuações de manutenção prioritária. Desenhada a estrutura da matriz, os fatores de risco identificados são avaliados qualitativamente, em termos de probabilidade e impacto, e posicionado na matriz, indicando seu "estado": eminente, crítico, alto, médio e baixo. São analisados dois sistemas de distribuição reais da classe de $13,8 \mathrm{kV}$, com o objetivo de demonstrar a capacidade da metodologia de encontrar as soluções condizentes do ponto de vista técnico e econômico. Os resultados apontam uma redução dos indicadores de continuidade, colaborando assim na eficaz gestão do sistema elétrico e na mitigação dos prejuízos econômicos associados às interrupções de energia.

\section{Palavras-chave}

Confiabilidade; matriz de risco; planejamento da manutenção; redes de distribuição. 


\section{Abstract}

Ferreira, Monique Ianne Jordão Ferreira; Leite da Silva, Armando Martins (Advisor). Maintenance Scheduling of Distribution Networks Based on Reliability Indices. Rio de Janeiro, 2019. 85p. MSc. Dissertation Departamento de Engenharia Elétrica, Pontifícia Universidade Católica do Rio de Janeiro.

Faults can occur in the electrical power system which will result in interruption of the power supply to consumers connected to these systems. An electric power utility should provide its customers with a service that is reliable and of good quality. Therefore, safe and efficient planning is necessary to obtain the reliability of the electrical system according to the requirements established by the regulatory agency of the sector. In case they are not observed by the electrical energy distributor, monetary penalties are possibly applied. The performance of a system can be observed based on the history of interruptions, through the continuity indicators. The low operational flexibility of substations, coupled with the network configurations, reduces the reliability of the systems causing monetary damage to companies and consumers, due to their vulnerability to interruptions of energy. The present study is essential because it aims to identify methods and analysis that detect the priority points for maintenance in the electric networks. In this way, the dissertation presents a methodology that identifies the equipment and sections associated to the critical points of greater impact in a distribution network. Thus, it is possible to direct the maintenance services of the circuits to the segments of greater impact in the indices of continuity of a certain region and to optimize the corresponding budget. The basic tool used to analyze the indices is a risk matrix, where the axes represent the probability of occurrence (recurrence) and company impact (continuity indices), in order to capture more precisely the points for priority maintenance actions. When the matrix structure is established, the identified risk factors are qualitatively assessed in terms of probability and impact, and positioned in the matrix, indicating their "state": eminent, critical, high, medium, and low. Two real distribution systems of the $13.8 \mathrm{kV}$ class are analyzed to demonstrate the ability of the proposed methodology to find the appropriate solutions from a technical and economic point of view. The results point to a reduction in continuity indicators, thus contributing to the effective management of the power electric system and mitigating the economic losses associated with power outages.

\section{Keywords}

Reliability; risk matrix; maintenance scheduling; distribution networks. 


\section{Sumário}

$\begin{array}{ll}\text { Resumo } & 5\end{array}$

$\begin{array}{lr}\text { Abstract } & 6\end{array}$

1 Introdução 14

1.1 Considerações Iniciais 14

1.2 Estado da Arte - Sistemas de Distribuição 17

1.3 Estrutura da Dissertação 23

2 Confiabilidade de Sistemas de Distribuição 24

2.1 Considerações Iniciais 24

2.2. Conceitos Básicos 25

$\begin{array}{ll}2.3 \text { Equipamentos de Proteção } & 27\end{array}$

2.4 Índices de Confiabilidade 29

2.4.1 Setor Elétrico Mundial 31

2.4.2 Setor Elétrico Brasileiro 33

2.4.2.1 Índices de Continuidade Individual 35

2.4.2.2 Índices de Continuidade Coletiva 36

2.4.2.3 Cliente Hora-Interrompido 37

2.5 Conclusões 38

3 Planejamento da Manutenção via Matriz de Risco 40

3.1 Introdução 40

3.2 Serviços de Manutenção 41

3.3 Metodologia Proposta 43

3.3.1 Matriz de Risco 45

3.3.2 Eixos de Reincidência e Impacto 46

3.3.3 Procedimentos 48

3.3.4 Descrição do Funcionamento da Metodologia 49

3.4 Conclusões 51 
4 Aplicação da Metodologia Proposta 53

4.1 Introdução 53

4.2 Planejamento da Manutenção 53

4.3 Sistema-Teste 56

4.2.2 Resultados 58

4.3 Planejamento da Rede 62

$\begin{array}{ll}\text { 4.3.1 Sistema-Teste } & 63\end{array}$

4.3.2 Resultados $\quad 65$

$\begin{array}{ll}4.4 \text { Conclusão } & 72\end{array}$

5 Conclusões $\quad 73$

$\begin{array}{ll}\text { Referências Bibliográficas } & 76\end{array}$

$\begin{array}{ll}\text { Apêndice } & 83\end{array}$ 


\section{Lista de Figuras}

Figura 1.1 - Níveis Hierárquicos [13]. 19

Figura 3.1 - Metodologia da Matriz de Risco. 44

Figura 3.2 - Matriz de Risco. 45

Figura 3.3 - Relação dos equipamentos e níveis de prioridade. 50

Figura 3.4 - Matriz de Risco. $\quad 50$

Figura 3.5 - Plano de ação.

Figura 4.1 - SETD: destaque LDA Cotiara [65]. 57

Figura 4.2 - Configuração da rede de distribuição. 57

Figura 4.3 - Matriz de Risco do circuito teste. 59

Figura 4.4 - Curva do DEC 2016 versus 2017.

Figura 4.5 - Redução da compensação financeira. $\quad 62$

Figura 4.6 - Diagrama SETD: destaque LDA Coringa. 63

Figura 4.7 - Diagrama de distribuição LDA Coringa [65]. 64

Figura 4.8 - Visão aproximada diagrama de distribuição LDA Coringa [65]. 64

Figura 4.9 - LDA Coringa: Regiões de maiores defeitos [65]. 65

Figura 4.10 - Matriz de Risco do circuito teste. 66

Figura 4.11 - Alteração 1: LDA Coringa [65]. 68

Figura 4.12 - Alteração 2: LDA Coringa [65]. 68

Figura 4.13 - Alteração 3: LDA Coringa [65]. 69

Figura 4.14 - Alteração 4: LDA Coringa [65]. 69

Figura 4.15 - Curva do DEC 2016 versus 2017.

Figura 4.16 - DEC LDA Coringa. $\quad 71$

Figura 4.17 - Compensação Financeira LDA Coringa. 71

Figura 7.1 - Diagrama Original da SETD [65]. 83

Figura 7.2 - Diagrama de distribuição [65].

Figura 7.3 - LDA Cotiara: Visão Total [65]. 85

Figura 7.4 - LDA Coringa: Visão Total [65]. 85 


\section{Lista de Tabelas}

Tabela 3.1- Níveis e pesos para o eixo Reincidência. 47

Tabela 3.2 - Níveis e pesos para o eixo de Impacto. 48

Tabela 3.3 - Relação dos equipamentos com reincidências e indicadores. $\quad 49$

Tabela 4.1 - Níveis de impacto do sistema teste. 58

Tabela 4.2 - Trechos e/ou equipamentos com risco inerente. 59

Tabela 4.3 - Níveis de impacto do sistema teste. 66

Tabela 4.4 - Trechos e/ou equipamentos com risco inerente. 67 


\section{Lista de Abreviaturas}

AENS

ANEEL

ASAI

ASUI

BT

CAIDI

CAIFI

$\mathrm{CF}$

$\mathrm{CHI}$

DEC

DIC

DICRI

DJ

DMIC

DNAEE

ENS

EPE

F\&D

FEC

FIC

FSS

ISE

LDA

LOLC

MBC

MT

NH1

$\mathrm{NH} 2$

ONS

RD

RCM
Average Energy not Supplied

Agência Nacional de Energia Elétrica

Average Service Availability Index

Average Service Unavailability Index

Baixa Tensão

Customer Average Interruption Duration Index

Customer Average Interruption Frequency Index

Chave-Fusível

Cliente Hora Interrompido

Duração Equivalente do Consumidor

Duração de Interrupção do Consumidor

Duração de Interrupção Individual

Disjuntor

Duração Máxima de Interrupção Contínua por Unidade

Consumidora

Departamento Nacional de Águas e Energia Elétrica

Energy not Supplied

Empresa de Pesquisa Energética

Frequência e Duração

Frequência Equivalente do Consumidor

Frequência de Interrupção do Consumidor

Frequência Simples Sustentável

Interrupção em Situação de Emergência

Linha de Distribuição Aérea

Loss of Load Cost

Manutenção Baseada em Confiabilidade

Média Tensão

Nível Hierárquico 1

Nível Hierárquico 2

Operador Nacional do Sistema Elétrico de Potência

Religador

Reliability Centered Maintenance 
SAIDI

SAIFI

SENDI

SEP

SETD

SGC

SL

TI

VBA

ZNA
System Average Interruption Duration Index

System Average Interruption Frequency Index

Seminário Nacional de Distribuição de Energia Elétrica

Sistema Elétrico de Potência

Subestação de Transmissão e Distribuição

Subgrupo de Confiabilidade

Seccionalizador

Transformador de Isolamento

Virtual Basic for Applications

Transformador 


\section{Lista de Símbolos}

\begin{tabular}{|c|c|c|}
\hline & $A$ & Disponibilidade \\
\hline & $U$ & Indisponibilidade \\
\hline & $\mu$ & Taxa de reparo \\
\hline & $\lambda$ & Taxa de falha \\
\hline & $r$ & Tempo médio de reparo \\
\hline & $N$ & Número de clientes \\
\hline & $t$ & Tempo \\
\hline & $i$ & Índice de interrupção na unidade consumidora \\
\hline & $T_{m}$ & Tempo médio de restauração \\
\hline & $C_{c}$ & Número máximo de clientes do alimentador \\
\hline ঠু & $C_{j}$ & $\begin{array}{l}\text { Número de clientes interrompidos associados ao equipamento d } \\
\text { proteção } \mathrm{j}\end{array}$ \\
\hline$\frac{\pi}{n}$ & $L_{i}$ & Carga \\
\hline 苂 & $N_{E P}$ & Número de equipamentos no alimentador \\
\hline مَّ & $N_{D J}$ & Número de disjuntor no alimentador \\
\hline : & $N_{R D}$ & Número de religadores no alimentador \\
\hline : & $N_{S L}$ & Número de seccionalizador no alimentador \\
\hline 1 & $N_{C F}$ & Número de chave-fusível no alimentador \\
\hline ปُ & $N_{T I}$ & Número de transformador de isolamento no alimentador \\
\hline & $N_{Z N A}$ & Número de transformador no alimentador \\
\hline
\end{tabular}




\section{Introdução}

\section{1 \\ Considerações Iniciais}

A partir da década de 1970, as privatizações foram ensejadas pelos debates ocorridos em função das consequências da privatização e dos diferentes modelos que visavam implementá-la. Nessa época, iniciavam-se as discussões sobre as consequências de privatização de monopólios naturais e os diferentes modelos para torná-la viável. No Brasil, a transição para uma nova política de energia, iniciada na década de 90, sofreu várias influências [1].

Nas últimas décadas, as redes de distribuição receberam uma atenção especial em relação à reestruturação e privatização do setor elétrico. A regulação e as políticas das empresas tiveram como resultados: o atendimento da expansão do sistema, inclusão de novos consumidores através da universalização do serviço e o estabelecimento de padrões de qualidade, buscando melhorar os indicadores de desempenho. Mais recentemente, esses sistemas voltaram ao centro das atenções devido às arquiteturas inteligentes (e.g., smart/micro grids) que integram e permitem ações de maior transparência a todos os usuários a elas conectados. As distribuidoras têm passado por muitas mudanças, mas sempre buscando por uma maior eficiência, no sentido de maximizar seus lucros, mantendo a qualidade de serviço em conformidade com as normas impostas pelas agências reguladoras.

Foram assinados contratos de concessão entre o Poder Concedente - Agência Nacional de Energia Elétrica (ANEEL) e as concessionárias de energia elétrica, que estabeleceram um conjunto de exigências, obrigações, procedimentos, indicadores de natureza técnica e comercial, além de penalidades, objetivando assegurar a qualidade dos serviços prestados pelas concessionárias aos consumidores. A legislação passou então a estabelecer limites/metas para cada uma das empresas concessionárias, de acordo com seu histórico, visando preservar e até mesmo aumentar a qualidade do fornecimento antes da privatização [2]. 
As mudanças na estrutura do setor elétrico levam à necessidade de um maior controle de qualidade de energia elétrica fornecida aos consumidores finais. As distribuidoras, portanto, trabalham em ambientes regulados necessitando justificar investimentos e tarifas, e ainda, obter eficiência econômica reduzindo custos de investimento. Esta redução, se não planejada, pode acarretar a diminuição na qualidade e no fornecimento de energia que deve obedecer a dois conceitos básicos, normalmente denominados qualidade de serviço e qualidade do produto.

A qualidade do serviço, entendida como a continuidade de fornecimento, é fruto de interrupções no sistema elétrico, provocadas por falhas no sistema (manutenção corretiva) e por atividades de manutenção programada (manutenção preventiva), em função de serviços necessários a serem realizados no sistema [3].

A qualidade do produto é caracterizada basicamente pela forma de onda de tensão dos componentes de um sistema trifásico e contempla basicamente os seguintes fenômenos: variação da frequência, variações de tensão de longa duração, variações de tensão de curta duração, distorções harmônicas de tensão e corrente, desequilíbrios de tensão e corrente e flutuações de tensão [3].

Os aspectos de qualidade de fornecimento são enfatizados na continuidade e são relacionados com a quantidade de interrupções e o tempo de retorno da energia. Esses indicadores podem ser individuais ou coletivos. Como exemplo de índices coletivos no Brasil, podem ser citados: Duração de Interrupção por Unidade Consumidora (DEC) e Frequência de Interrupção por Unidade Consumidora (FEC); representam respectivamente o tempo médio de duração das interrupções por consumidor e a frequência média de interrupções por consumidor. No tocante aos indicadores individuais, os seguintes índices de desempenho são considerados no Brasil: Duração de Interrupção do Consumidor (DIC) e Frequência de Interrupção do Consumidor (FIC); representam respectivamente os valores individuais para tempo e frequência de interrupção.

Muitas distribuidoras possuem dificuldades para avaliar o desempenho dos seus sistemas de distribuição via indicadores, principalmente do ponto de vista preditivo. Ademais, grandes esforços ainda necessitam ser feitos na utilização desses índices, sobretudo para aferir economicamente obras para melhoria na rede, manutenções e reforços. 
Do ponto de vista da avaliação preditiva, métodos de enumeração de estados [4], [5] e simulação Monte Carlo [6], ambos baseados nos Processos de Markov [7], foram criados na década de 80, em conjunto com diversos indicadores de desempenho. Tais métodos e índices de confiabilidade [8] têm sido utilizados e aplicados amplamente em sistemas de geração e/ou transmissão dado à sua importância. Devido ao menor impacto nos sistemas de menor potência, redes de distribuição têm recebido uma atenção menor em estudos para realização de técnicas e avaliação de confiabilidade, quando comparados aos sistemas de geração e transmissão.

Geralmente uma interrupção no sistema de geração e transmissão atinge um grande número de consumidores, entretanto, o maior número de falhas e maior tempo de indisponibilidade do fornecimento de energia aos consumidores são na rede de distribuição. Mesmo falhas de poucos minutos, podem causar elevados prejuízos quando ocorrem de forma inesperada, se comparadas com interrupções previamente comunicadas e programadas. A regulação do setor elétrico brasileiro não exige atendimento do critério "N-1" [9] para distribuição/subtransmissão, com isso, há redes com poucos recursos e subestações com pouca flexibilidade operativa, que resulta em indisponibilidades do sistema.

O estudo do planejamento da expansão do sistema elétrico é realizado de forma segmentada: geração e transmissão, realizado pela Empresa de Pesquisa Energética (EPE), com participação do Operador Nacional do Sistema Elétrico (ONS) e agentes do setor. Já o planejamento da distribuição é de responsabilidade exclusiva das empresas distribuidoras (concessionárias) de energia elétrica [10].

Dada a impossibilidade de se acabar com as interrupções no fornecimento de energia elétrica, um planejamento eficiente da manutenção se faz necessário, visando decidir onde e quando atuar de forma assertiva, para evitar interrupções e garantir a qualidade no atendimento das metas estabelecidas pelo órgão regulador. Um dos grandes desafios para os engenheiros responsáveis pela execução de serviços de manutenção em sistemas elétricos de potência é encontrar o ponto ideal entre a realização do serviço com o menor custo e garantir maior confiabilidade possível.

Cada distribuidora tem um orçamento disponibilizado para manutenção de sua rede. Grandes investimentos resultam em custos elevados e, portanto, tarifas 
altas. Em contrapartida, poucos investimentos, fazem com que a rede fique vulnerável às causas de fenômenos naturais, ação de terceiros e sobrecargas nas linhas e equipamentos. Muitas vezes, devido às restrições orçamentárias, faz-se necessário o uso de metodologias que permitam ações assertivas de manutenção de menor custo de modo a se atingir a melhor confiabilidade possível: i.e., menor quantidade de defeitos e/ou menor duração da interrupção.

Ao usar o histórico de ocorrências de um sistema de distribuição de energia, é possível adotar uma metodologia que identifica os equipamentos e trechos que correspondem a pontos críticos e de maior impacto da rede elétrica visando direcionar os serviços de manutenção de circuitos para os trechos de maiores impactos nos indicadores da região e ainda, otimizar o orçamento correspondente.

Para grandes clientes (empresas de grande porte, e.g., hospitais) já é possível escolher a concessionária fornecedora de energia, e, numa possível evolução da regulação do setor elétrico, isso será possível também para clientes residenciais e empresas de pequeno porte. Neste contexto, a aplicação da metodologia proposta é essencial para melhorar os índices de continuidade.

\section{2 \\ Estado da Arte - Sistemas de Distribuição}

No final da década de 60, principalmente na Europa (e.g., UK, Itália e França) e na América do Norte, iniciaram-se estudos de metodologia probabilística para avaliação de desempenho de sistemas elétricos. No Brasil, no final da década de 70 , através da Portaria 46/1978 do Departamento Nacional de Águas e Energia Elétrica (DNAEE) [11], a qualidade de energia ganha definição no contexto nacional com o estabelecimento de metas para duração e frequência de interrupção do fornecimento de energia acima de 3 minutos. Nesta portaria já constavam as definições de DEC e FEC, bem como conjunto de consumidores. Os valores das metas desses indicadores foram estipulados com base no padrão de rede, tensão de atendimento e a classificação da região em urbana ou rural. Em 1982, com a criação do Subgrupo de Confiabilidade (SGC), a aplicação de metodologia probabilística ganhou força no Brasil [12]. Gradativamente, a natureza estocástica dos fenômenos causadores de indisponibilidade foi reconhecida e devido à escassez de recursos 
financeiros, que levou a uma análise mais detalhada do comportamento do sistema, os critérios determinísticos foram substituídos por avaliação de risco [10].

Antes da década de 70, as concessionárias de energia elétrica utilizavam os dados históricos para projetar melhorias na qualidade de energia, medida em interrupções e quantidade de horas de energia não fornecida. Não havia ferramenta ou instrumento legal para estabelecer os níveis adequados de qualidade de energia, além disso, a qualidade do fornecimento não era alvo de avaliação e acompanhamento para as áreas de atuação das distribuidoras.

Hoje em dia, as literaturas a respeito do cálculo de confiabilidade dos sistemas de potência mostram um equilíbrio entre as áreas de geração, transmissão e distribuição, o que não era verificado antigamente quando a avaliação da capacidade de geração atraía maiores atenções e consequentemente maior número de trabalhos publicados.

Nesse contexto, o sistema elétrico tem sido representado por níveis hierárquicos como mostra a Figura 1.1, seguindo a segmentação natural do setor, conforme mencionado na subseção anterior. O nível hierárquico 1 (NH1) é formado pelo segmento da geração. Este compreende também o nível hierárquico 0 (NH0), que se refere às fontes primárias de energia (água, vento, etc.). Tais níveis foram os que mais receberam atenção das publicações em confiabilidade. Há um revigoramento recente deste segmento principalmente pela inserção de fontes renováveis como eólica e solar. O nível hierárquico 2 (NH2) compreende os segmentos de geração e transmissão. Finalmente, a análise completa de confiabilidade engloba também o segmento de distribuição, definindo assim o nível hierárquico $3(\mathrm{NH} 3)$ [13].

As primeiras análises foram realizadas no NH1, onde é avaliado se a geração é suficiente para atender toda a carga do sistema, ignorando as demais limitações. Os estudos, envolvendo a criação de algoritmos computacionais de apoio, iniciaram nos segmentos de geração $(\mathrm{G})$, sendo depois estendidos à transmissão $(\mathrm{T})$ e posteriormente às análises compostas (G\&T), i.e., o NH2 propriamente dito [14][16]. Foram utilizados métodos analíticos, como a metodologia de enumeração de estados [5] e a simulação Monte Carlo [6]. 


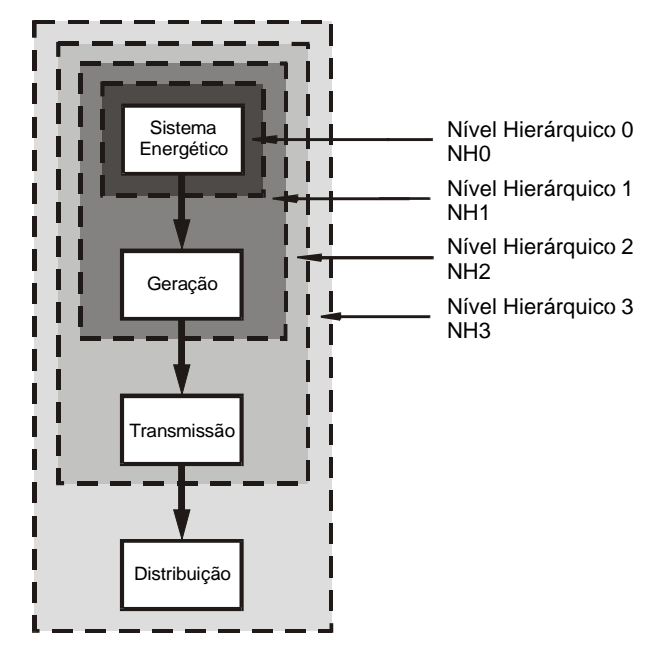

Figura 1.1 - Níveis Hierárquicos [13].

O interesse sobre as análises de confiabilidade nas áreas de transmissão e distribuição aumentou muito com o passar dos anos. As primeiras publicações mais significativas foram em 1964 através dos artigos [17], [18], que introduziram importantes indicadores [19], no cenário de avaliação de confiabilidade do sistema elétrico. Como é possível identificar em [7], as mudanças de tempo/clima têm sido também consideradas. A principal contribuição foi a introdução dos procedimentos de cálculo para frequência e duração média de falha. Estes dois indicadores formam as bases para avaliação da confiabilidade dos sistemas de distribuição, como se pode verificar em [20].

Técnicas de avaliação analítica através de modelos Markovianos para estimativa da confiabilidade de sistemas de transmissão foram apresentadas em [21], que considerou também o efeito do tempo adverso em simples configurações em paralelo e comparou com os resultados obtidos em [17].

Uma técnica analítica para determinar as distribuições de probabilidade, referentes ao número de falhas por ano e a duração das falhas para um ponto de carga, foi proposta em [22]. Entretanto, esta metodologia é aproximada e não apresenta uma expressão analítica para calcular a distribuição de probabilidades dos tempos de interrupção [19]. Nessa época, ainda não existiam publicações que retratassem o emprego de simulação Monte Carlo Cronológica, principalmente sequencial, para avaliação da confiabilidade dos sistemas de distribuição. 
As publicações mais significantes entre 1992 e 1996 estão em [23]. Em 1993, surge o primeiro artigo voltado para distribuição, onde é empregada a simulação Monte Carlo Cronológica para obtenção das distribuições de probabilidades dos índices de confiabilidade [24]. Após serem calculados, são comparados com o método analítico.

A referência [25] cita pela primeira vez a importância da manutenção preventiva, os autores demonstram os benefícios que esta prática gera a confiabilidade dos sistemas de distribuição. Os autores utilizam o conceito de Reliability Centered Maintenance (RCM) em sistemas de distribuição de energia elétrica. Outros desdobramentos foram também publicados por esses autores na linha de RCM, a qual não será utilizada nesta dissertação.

O conceito RCM também tem sido utilizado no Brasil [26], por exemplo, através de um aplicativo informatizado para associar às taxas de falhas dos materiais existentes, devidamente separadas na parte corretiva e preventiva, decorrente de uma análise global dos materiais pela metodologia RCM, em cada bloco, em função da quantidade dos materiais existentes. Uma básica referência no assunto RCM pode ser apreciada em [27].

Em 2004, foi apresentado um trabalho no Seminário Nacional de Distribuição de Energia Elétrica (SENDI) [27] onde a proposta era realizar a "inspeção filmada", assim, seria possível visualizar por cima da rede e estrutura, pontos que necessitam de manutenção que não são possíveis identificar visualmente. Atualmente já estão sendo utilizados drones ${ }^{1}$ para essa atividade. Esta linha de avaliação não será seguida por esta dissertação, embora possa ser considerada como uma complementação das técnicas de identificação de trechos críticos da rede de distribuição a ser descrita no presente trabalho.

Em 2006, um estudo foi publicado com o objetivo de definir diretrizes e estratégias de manutenção, determinando os trechos críticos da rede de distribuição, baseado nas ocorrências que impactaram o indicador FEC no período considerado, dessa forma prioriza-se a realização de inspeções visuais e instrumentais. A ferramenta utilizada foi uma folha de coleta de dados, gráfico de Pareto, diagrama

\footnotetext{
${ }^{1}$ Veículo aéreo não tripulado controlado por controle remoto. Geralmente contém câmera para filmagens e fotografias para vistas aéreas.
} 
de causa e efeito, histograma e diagrama de dispersão [28]. Aspectos interessantes são abordados neste trabalho.

Como previamente mencionado, vários trabalhos foram publicados avaliando-se as probabilidades de perda de carga, energia esperada não suprida, frequência e duração (F\&D) e modos de falhas dos desligamentos de sistemas acadêmicos e sistemas reais [30]-[32]. Fica clara a importância dos modelos de Markov e técnicas analíticas e de simulação Monte Carlo [4]-[6], [32] na avaliação de indicadores ou índices confiabilidade em sistemas de distribuição de energia elétrica de forma preditiva. Nessa linha de pesquisa, vários modelos e aplicações têm sido desenvolvidos no Brasil (e.g., ver as seguintes dissertações/ teses [33]-[37] e trabalhos técnicos associados [38]-[49]) e em outros países (disponíveis através de sites do tipo IEEE Xplore). No Brasil, atualmente, há uma tendência na utilização da simulação Monte Carlo sequencial devido à existência de índices do tipo DMIC - Duração Máxima de Interrupção Contínua por unidade consumidora ou ponto de conexão (ver Capítulo 2) [35], [36].

Nos novos contratos de concessão de distribuição, o foco é a continuidade do fornecimento de energia, pois se as concessionárias não atenderem aos limites de DEC e FEC estipulados pelo órgão regulador, podem perder a concessão ou ter a distribuição de suas ações reduzidas ao mínimo regulamentado [19]. Assim sendo, a avaliação da confiabilidade se torna ainda mais importante, necessitando não apenas explorar a melhoria do desempenho das redes de distribuição, mas também avaliando os pontos mais críticos de um sistema, para atuação com o menor custo possível.

Recentemente [37], [49], foi proposto um método que identifica, em uma avaliação de confiabilidade conjunta entre transmissão e subtransmissão, as regiões com maior necessidade de investimentos em reforços e melhorias. A metodologia desenvolvida, baseada em simulação Monte Carlo, permite propor melhores estratégias para reconfiguração e expansão do sistema; alocação de dispositivos de seccionamento nas subestações melhorando flexibilidade operativa e automatização de equipamentos, reduzindo tempos de restabelecimento; substituição de equipamentos obsoletos e melhorias na gestão dos ativos, aumentando o nível de confiabilidade. De posse de informações como indicadores de continuidade, compensações financeiras pagas, nível de depreciação dos 
equipamentos em operação (valor na base de remuneração da concessionária), custos de aquisição e substituição/instalação de novos equipamentos, pode ser feito um estudo técnico-financeiro que irá subsidiar decisões de alocação de recursos no sistema elétrico de forma a se obterem os melhores resultados para a companhia e para a sociedade.

Para técnicas de manutenção de redes de distribuição não há muitas referências, principalmente aquelas que utilizam os tradicionais índices FEC, DEC, etc., os quais podem ser obtidos a partir de históricos de desempenho da rede de distribuição ou, preditivamente conforme já descrito, por técnicas analíticas e de simulação Monte Carlo baseadas em modelos de Markov.

Este trabalho propõe apresentar uma nova metodologia que identifica os equipamentos e trechos do sistema de distribuição que correspondem a pontos críticos e de maior impacto em uma rede, visando direcionar os serviços de manutenção de circuitos para aqueles equipamentos elétricos ou segmentos de maior impacto nos indicadores da região, além da otimização do orçamento correspondente. O conceito de Matriz de Risco [50], [51] será utilizado como base da metodologia, cujos eixos apresentam: probabilidades de ocorrência (reincidência) e impacto corporativo (indicador de continuidade).

A avaliação dos fatores de risco é uma das etapas de qualquer processo de gerenciamento. A alocação dos níveis é feita de acordo com o histórico de falhas dos alimentadores de uma determinada região, o tempo médio de atendimento e o máximo número de clientes interrompidos por atuação da principal proteção de cada rede de distribuição. Cada um dos fatores de risco identificado é avaliado qualitativamente, em termos de probabilidade e impacto, e posicionado na matriz, indicando o fator de risco (eminente, crítico, alto, médio e baixo). Tal matriz aponta os trechos da rede que devem ser tratados com prioridade e será exemplificada em um sistema real. Uma avaliação detalhada da metodologia será mostrada no Capítulo 3. 


\section{3 \\ Estrutura da Dissertação}

Esta dissertação está dividida em cinco capítulos que serão resumidamente descritos a seguir.

Este capítulo abordou o problema de como atuar de forma assertiva na manutenção para minimizar os tempos e impactos da interrupção do fornecimento de energia por falhas no sistema elétrico. Foram também abordadas de forma resumida as técnicas empregadas da solução do problema proposto.

O Capítulo 2 apresenta os conceitos de confiabilidade de sistemas de distribuição, os tradicionais índices de continuidade bem como os equipamentos de proteção que compõem esse sistema.

O Capítulo 3 apresenta a metodologia proposta baseada no conceito de Matriz de Risco para aplicação no planejamento da manutenção das redes de distribuição e custos de investimento. São descritos os índices utilizados nesta avaliação.

No Capítulo 4 é descrita a aplicação da técnica proposta no Capítulo 3 em um sistema teste real, tendo em vista o planejamento da manutenção e também o planejamento de rede. Neste capítulo serão apresentadas as principais considerações, discussões sobre os resultados e as possíveis restrições dos modelos e métodos propostos.

Finalmente no Capítulo 5, são apresentadas as principais conclusões sobre a metodologia proposta com sugestões de continuação do tema em trabalhos futuros.

As referências bibliográficas utilizadas nesta dissertação são apresentadas após o capítulo de conclusões e, por último, os diagramas completos utilizados no Capítulo 4 são mostrados em Apêndice. 


\section{2 \\ Confiabilidade de Sistemas de Distribuição}

\section{1 \\ Considerações Iniciais}

No capítulo anterior foi feita uma introdução ao problema em questão, apresentado estado da arte e a estrutura da dissertação. Neste capítulo, é tratada a confiabilidade dos sistemas de distribuição de energia. Esses sistemas são possíveis de serem averiguados sob o ponto de vista da oferta de energia até o consumidor final. Isso se dá através de indicadores ou índices. Há vários modelos utilizados até então para análise desses indicadores do sistema elétrico. Essa seção faz uma breve descrição dos conceitos de confiabilidade associados às redes de distribuição.

Nas redes de distribuição são instalados equipamentos de proteção em pontos estratégicos para que, em caso de falhas ou manutenções no sistema, a corrente seja interrompida e a área desenergizada seja reduzida ao máximo. Assim, em caso de defeitos na rede, há sempre uma tentativa da redução dos tempos de interrupção e do número de clientes sem energia, além de proteger o sistema elétrico de defeitos transitórios ou que necessitam de impedimento de trecho.

Nesse contexto, as interrupções do fornecimento de energia são mensuradas em forma de indicadores de continuidade, tanto no setor elétrico mundial quanto no setor elétrico brasileiro. Para isso, o órgão regulador, que no caso brasileiro é a ANEEL, estabelece exigências para assegurar a qualidade do serviço prestado a partir de metas que se não forem atingidas, podem ser convertidas em penalidades.

A seguir, os conceitos são apresentados com maior riqueza de detalhes. 


\section{2. Conceitos Básicos}

A probabilidade de sucesso no atendimento à demanda dos consumidores por parte de uma concessionária de energia elétrica está diretamente relacionada com o custo dos investimentos e manutenções da rede elétrica. Por sua vez, a confiabilidade está expressa na forma da qualidade e na oferta contínua de energia, o que demanda grandes investimentos. Todavia, grandes investimentos podem gerar um elevado custo financeiro. Já os baixos investimentos, podem potencializar a vulnerabilidade do sistema elétrico quanto às interrupções de energia.

Da privatização de grande parte das empresas distribuidoras e também de inserção de mecanismos de competição no setor de geração, surgiu a necessidade de órgãos reguladores para o estabelecimento de novas regras para a prestação dos serviços públicos de fornecimento de energia elétrica aos consumidores finais [3]. Dessa forma, com o surgimento de novas regras para a prestação de serviços, as concessionárias passaram a ter metas a serem cumpridas para atender o mínimo da qualidade de energia para atendimento aos seus clientes. O desafio é atender a boa qualidade no fornecimento de energia com o menor custo de investimento.

O sistema elétrico está sujeito a falhas, seja por ação de terceiros, por fenômenos da natureza ou ainda má qualidade dos equipamentos e estruturas instalados na rede. Essas estruturas, por sua vez, podem comprometer o fornecimento de energia aos consumidores. Por isso, as concessionárias devem garantir que essas falhas não aconteçam visando à continuidade e qualidade do sistema e, assim, cumprindo com as exigências estabelecidas pela agência reguladora do setor elétrico, ANEEL. Faz-se necessário, portanto, um planejamento eficiente dos serviços de manutenção que deve decidir onde e quando atuar de forma assertiva para evitar interrupções e garantir a qualidade do serviço prestado. Cumpre destacar então a importância da confiabilidade no sistema elétrico. Confiabilidade é a capacidade de um dispositivo desempenhar seu propósito durante o período de tempo desejado, sob condições operativas encontradas [4]. As condições operativas estão expressas no sistema elétrico de potência.

Como já mencionado no Capítulo 1, o sistema elétrico de potência (SEP) pode ser divido em geração, transmissão e distribuição. A área da geração transforma uma energia mecânica, hidráulica ou térmica, em energia elétrica. Após essa etapa, 
o setor de transmissão tem a função de transportar essa energia aos principais centros de carga. Nestes centros, os sistemas de transmissão chegam por meio de subestações e se transformam em sistema de distribuição. Este, por sua vez, é responsável por interligar os sistemas de grande porte, formados pela geração e transmissão, com os consumidores finais [3].

Falhas na geração e transmissão acarretam no desligamento de grande quantidade de consumidores, enquanto as falhas na distribuição interrompem o fornecimento de energia em pontos localizados. Entretanto, o sistema de distribuição é responsável por aproximadamente $90 \%$ dos problemas de confiabilidade e que afetam os consumidores [4], [32].

Uma rede de distribuição pode ser aérea ou subterrânea, sendo a aérea predominante. A rede subterrânea é mais utilizada em áreas de maior densidade de carga como, por exemplo, o centro de uma grande cidade.

Do ponto de vista da confiabilidade, a rede de distribuição pode ser representada por meio de componentes conectados em série, em paralelo, ou ainda por uma combinação qualquer dos componentes [4], [32]. Existem vários métodos disponíveis para solução e avaliação destas redes [4]. As redes aéreas podem ser representadas com diferentes topologias [3]. São elas:

i) Radial: o sistema radial simples consiste na alimentação do circuito por apenas um lado de sua extremidade; existe um único caminho para alimentar o circuito. Por esse motivo, apresenta desvantagens quando há ocorrência de defeitos, pois é necessário que o alimentador esteja desenergizado para que seja feita a manutenção. Com isso, os consumidores que se localizam no final deste circuito sofrem todas as interrupções causadas por defeitos permanentes;

ii) Fechado em anel: o alimentador primário inicia na subestação, estendendo-se pela área a ser alimentada voltando à mesma subestação. Dele podem ser derivados ramais para cobrir toda a região requerida. Apresentam-se também com vários disjuntores, religadores e chaves seccionadoras; 
iii) Radial com recurso ou mista: a partir do sistema radial simples, há ramificações para instalação de novas cargas, e com isso, novos recursos. Vários pontos de recursos são criados ao longo do alimentador até mesmo como interligação a outro circuito. Sendo assim, esse sistema permite que um número menor de consumidores seja interrompido em caso de ocorrência de defeitos ou manobras para manutenção.

$\mathrm{Na}$ ocorrência de falhas ou manutenções programadas, visando o menor número de consumidores com energia interrompida, são instalados equipamentos de proteção e seccionamento em pontos estratégicos de uma rede de distribuição.

\section{3 \\ Equipamentos de Proteção}

A proteção do sistema elétrico, em redes de distribuição, tem como finalidade, isolar o curto-circuito o mais próximo possível do ponto em que foi originado e assim interromper o fornecimento de energia para o menor número de consumidores possível [52].

Em casos de defeitos na rede há a redução dos tempos de interrupção e de clientes sem energia, além de proteger o sistema elétrico de defeitos transitórios ou que necessitem de impedimento de trecho. São esses equipamentos que definem os trechos dos circuitos [53]:

i) Disjuntor (DJ): instalado como proteção principal do circuito e a abertura deste interrompe todos os clientes conectados a esse alimentador. O disjuntor consegue operar, interrompendo o alimentador, a plena carga e em vazio, e energiza os mesmos alimentadores em operação normal ou em falta;

ii) Religador (RD): pode ser instalado como proteção principal ou no meio de um circuito, são capazes de realizar automaticamente a abertura e fechamento dos seus contatos principais e podem ser telecomandados. É um equipamento capaz de realizar automaticamente abertura e fechamento de seus contatos principais. A quantidade de religamentos e 
o tempo de ajuste para cada um é definido de acordo com os ajustes dos outros equipamentos em série;

iii) Seccionalizador (SL): instalado no meio de um circuito ou em ramais, também é capaz de realizar abertura e fechamento dos seus contatos automaticamente a partir de um equipamento de retaguarda. Sua função é seccionar parte de um alimentador submetido a uma falta permanente, enquanto um equipamento de retaguarda fica responsável pela interrupção da corrente resultante do mencionado defeito;

iv) Chave-Fusível (CF): possui um elo fusível, que ao passar uma corrente por ele maior do que sua especificação, o mesmo se funde, cessando assim, a passagem de corrente e também o fornecimento de energia;

v) Transformador de Isolamento (TI): além da função de abaixar a tensão de 13,8 kV trifásica para 7,2 kV fase-neutro, instalado em áreas rurais, o mesmo possui uma chave-fusível acoplada que abre em caso de defeitos no trecho a jusante do TI. É instalado somente em áreas rurais onde a demanda de carga é pequena;

vi) Transformador (ZNA ou zona): com a função de abaixar a tensão de 6, 7,2 e 13,8 kV para 127/220V, podem ser convencionais, onde possuem uma chave-fusível acoplada, ou do tipo auto protegido, onde possui um disjuntor interno que também desarma em caso de falhas.

A alocação de equipamentos de proteção e seccionamento em pontos estratégicos no sistema de distribuição contribuem para a qualidade do fornecimento de energia restringindo ao máximo as áreas desenergizadas fazendo com que aumente a confiabilidade do sistema elétrico. A confiabilidade pode ser mensurada através de índices/indicadores. 


\section{4 \\ Índices de Confiabilidade}

Confiabilidade está relacionada à capacidade do elemento de proteção cumprir com segurança e exatidão as funções que lhe foram confiadas [53]. Quando o sistema está bem ajustado, projetado e coordenado, apresenta vantagens à rede: menor número de desligamentos, facilidade de manobras, redução no tempo de restabelecimento e, como consequência, a melhor satisfação do cliente e o aumento do faturamento da empresa.

Uma distribuidora deve fornecer energia elétrica aos consumidores obedecendo à qualidade do serviço e do produto. A qualidade do serviço prestado é definida como a continuidade do fornecimento, que inclui também o atendimento, e que pode ser abalada pelas interrupções no sistema elétrico provocadas por falhas ou atividades de desligamentos programadas para atuação da manutenção. Qualidade do produto, por sua vez, caracteriza-se pela forma de onda de tensão dos componentes de um sistema trifásico, como: variação de frequência, variação de tensão, desequilíbrios de tensão, correntes, harmônicos e flutuações de tensão [3].

As interrupções de energia causam interrupções individuais ou coletivas, onde em ambos os casos, se a interrupção for maior que três minutos [54], gerará um indicador de continuidade, e assim, a necessidade de compensar financeiramente um ou mais clientes, caso a meta estipulada pelo órgão regulador, de continuidade individual ou coletiva, seja violada.

Visando manter a qualidade na prestação do serviço público de distribuição de energia elétrica, a ANEEL exige que as concessionárias mantenham um padrão de continuidade e, para tal, edita limites para os indicadores coletivos de continuidade [55].

A continuidade do fornecimento é avaliada através de indicadores individuais e coletivos. Normalmente, a qualidade do serviço é feita com base em alguns parâmetros como: valores de taxas de falhas dos equipamentos (número de vezes, em um determinado período que o equipamento deve falhar), taxa de falha equivalente $\left(\lambda_{S}\right)$, taxa de reparo $(\mu)$, tempos médios para atendimento de uma 
determinada ocorrência na rede entendido como tempo médio de reparo $\left(r_{S}\right)$ e a indisponibilidade equivalente $\left(U_{S}\right)[4]$.

A partir dos dados históricos dos equipamentos são definidas essas taxas e os valores de disponibilidade $(A)$ e indisponibilidade $(U)$, conforme equações [7]:

$$
A=\frac{\mu}{\lambda+\mu} \text { e } U=\frac{\lambda}{\lambda+\mu}
$$

Para um sistema de dois componentes, em que um consumidor necessita que todos os componentes entre ele e o ponto de suprimento estejam operando adequadamente, os parâmetros são [7], [33]:

$$
\begin{gathered}
\lambda_{S}=\lambda_{1}+\lambda_{2} \\
r_{S}=\frac{\lambda_{1} r_{1}+\lambda_{2} r_{2}}{\lambda_{1}+\lambda_{2}} \\
U_{S}=\lambda_{1} r_{1}+\lambda_{2} r_{2}
\end{gathered}
$$

Em um sistema série, quando ocorre a falha de um componente, o sistema fica inoperante. Para minimizar o número de equipamentos expostos às falhas, algumas redes de distribuição operam com sistemas paralelos. Dessa forma, basta que um componente esteja em operação para garantir o bom funcionamento do sistema [7], [33].

$$
\begin{gathered}
\lambda_{P}=\lambda_{1} \lambda_{2}\left(r_{1}+r_{2}\right) \\
r_{P} \cong \frac{r_{1} r_{2}}{r_{1}+r_{2}} \\
U_{P}=\lambda_{1} r_{1}
\end{gathered}
$$

A confiabilidade do sistema elétrico está relacionada com a sua configuração e flexibilidade em obter caminhos alternativos para o fornecimento de energia após uma contingência [10]. 
Esses parâmetros de confiabilidade são tratados no sistema elétrico por todo o mundo. Portanto, cabe um destaque sobre o setor elétrico mundial e o setor elétrico brasileiro quando tratam desses parâmetros.

\subsection{1}

\section{Setor Elétrico Mundial}

Os índices de confiabilidade apresentados anteriormente são valores esperados com base na distribuição de probabilidade, porém, não determinísticos, pois não conseguem representar o sistema de forma completa. Então, para considerar as interrupções e os tempos médios de restabelecimento de energia foram criados os índices SAIFI (System Average Interruption Frequency Index), CAIFI (Customer Average Interruption Frequency Index), SAIDI (System Average Interruption Duration Index) e CAIDI (Customer Average Interruption Duration Index) [4]:

$$
\begin{gathered}
\text { SAIFI } \left.=\frac{\sum \lambda_{i} N_{i}}{\sum N_{i}} \text { [interrupções } / \text { consumidor } \times \text { ano }\right] \\
\text { CAIFI }=\frac{\sum \lambda_{i} N_{i}}{\sum N_{a}}[\text { interrupções } / \text { consumidor afetado } \times \text { ano }]
\end{gathered}
$$

$$
\text { SAIDI }=\frac{\sum U_{i} N_{i}}{\sum N_{i}}[\mathrm{~h} / \text { consumidor } \times \text { ano }]
$$

$$
\text { CAIDI }=\frac{\sum U_{i} N_{i}}{\sum \lambda_{i} N_{i}}[\mathrm{~h} / \text { interrupção }]
$$


onde $\lambda_{i}$ é a taxa de falha (ocorrência/ano), $U_{i}$ é a indisponibilidade (hora/ano), $N_{i}$ é o número de consumidores de um ponto de carga $i$, sendo $N_{a}$ o número de consumidores afetado pela interrupção.

Os índices SAIFI e SAIDI juntos são os mais utilizados internacionalmente e identificados respectivamente por FEC e DEC no Brasil, como será discutido mais adiante. O SAIFI faz referência ao número total de interrupções de clientes em relação ao número total de clientes. Já o CAIFI faz referência ao número total de interrupções de clientes em relação ao número de clientes afetados.

O SAIDI é o somatório das durações das interrupções das unidades consumidoras dividido pelo total de clientes. O CAIDI é o somatório das durações das interrupções das unidades consumidoras dividido pelo número de interrupções de clientes [4].

O ASAI (Average Service Availability Index) - Disponibilidade média do serviço - indica a disponibilidade do serviço em horas em relação ao tempo de serviço demandado. O índice ASUI (Average Service Unavailability Index) Indisponibilidade média do serviço - indica a indisponibilidade do serviço em relação ao tempo de serviço demandado. São calculados conforme equações (2.12) e (2.13), respectivamente [4].

$$
\begin{aligned}
\mathrm{ASAI} & =\frac{\sum N_{i} \times 8760-\sum U_{i} N_{i}}{\sum N_{i} \times 8760} \\
\mathrm{ASUI} & =\frac{\sum U_{i} N_{i}}{\sum N_{i} \times 8760}=1-\mathrm{ASAI}
\end{aligned}
$$

O ASAI e ASUI são normalmente utilizados para realizar análise de tendências.

Outros índices considerados é a Energia não Suprida, ENS (Energy not Supplied) e Energia não Suprida por Consumidor, AENS (Average Energy not Supplied) são dados conforme equações (2.14) e (2.15) [4]:

$$
\mathrm{ENS}=\sum L_{i} U_{i}[\mathrm{kWh} / \mathrm{ano}]
$$




$$
\mathrm{AENS}=\frac{\sum L_{i} U_{i}}{\sum N_{i}}[\mathrm{kWh} / \text { consumidor } \times \text { ano }]
$$

O indicador que representa o custo pelo não fornecimento de energia a um consumidor ou para o sistema é dado por LOLC (Loss of Load Cost). Depende basicamente dos custos unitários de interrupção (UC, unit costs) de cada conjunto de consumidores e é dado em US\$/kWh [10].

$$
\mathrm{LOLC}=\mathrm{EENS} \times U C[\mathrm{R} \$ \text { ou US\$/ano }]
$$

Com base nos indicadores internacionais, a ANEEL estabeleceu para o setor elétrico brasileiro com vistas de mensurar a qualidade da oferta, do serviço e do produto oferecido pelas concessionárias de energia elétrica.

\subsection{2 \\ Setor Elétrico Brasileiro}

No Brasil, os índices de qualidade estão definidos em [55]. A agência reguladora divide o sistema elétrico em conjuntos. A definição de conjuntos parte da suposição que agrupamentos de consumidores têm seu nível de qualidade de serviço estabelecido em função de características físicas da rede e do mercado de energia [54]. São então definidas metas para as concessionárias a fim de atender a função básica de fornecimento de energia ao menor custo possível, impondo desafios para as distribuidoras melhorarem o atendimento ao cliente. Caso as concessionárias ultrapassem os limites estipulados, deverão pagar compensação financeira para os clientes afetados em forma de crédito na fatura de energia após a averiguação dos indicadores.

$\mathrm{Na}$ apuração dos indicadores devem ser consideradas todas as interrupções com duração igual ou maior que 3 (três) minutos e são admitidas apenas as seguintes exceções [55]: 
i) Falha nas instalações da unidade consumidora que não provoque interrupção em instalações de terceiros;

ii) Interrupção decorrente de obras de interesse exclusivo do consumidor e que afete somente a unidade consumidora do mesmo;

iii) Interrupção em situação de emergência (ISE ${ }^{2}$ );

iv) Suspensão por inadimplência do consumidor;

v) Racionamentos instituídos;

vi) Interrupções ocorridas em dia crítico ${ }^{3}$;

vii) Oriundas da atuação de esquema regional de alívio de carga estabelecido pelo ONS.

Os indicadores são apurados como índices de continuidade individual e de continuidade coletiva. Os de continuidade coletiva podem ser classificados como de ordem "acidental": são provenientes de falhas no sistema ou fenômenos da natureza (chuva, vento). Também estão entre os indicadores de continuidade coletiva os de ordem "programada", que são intervenções no sistema para manutenções preventivas ou melhoria na rede. As falhas ainda podem ser de origem interna da concessionária, ou externa, que por sua vez, são falhas ocorridas na geração, transmissão ou clientes.

Os indicadores podem ainda ser classificados em: "Percebido" (onde este inclui todas as interrupções) e "Regulatório" (onde são expurgadas todas as interrupções conforme definidas no item anterior).

Destacados os indicadores continuidade coletiva dentro do sistema elétrico brasileiro serão descritos os índices de continuidade individual e coletiva.

2 Refere-se a um evento que comprovadamente impossibilite a atuação imediata da distribuidora e que não tenha sido provocada ou agravada por ela, seguindo dois critérios: decorrente de evento associado ao Decreto de Declaração de Situação de Emergência ou Estado de Calamidade pública emitido por órgão competente ou decorrente cuja soma do CHI (Cliente-Hora-Interrompido) das interrupções seja superior a 2,612 $\times N^{0,35}$.

${ }^{3}$ A ANEEL reconhece que, caso ocorra uma eventualidade, e o número de ocorrências emergenciais por dia para um conjunto, ultrapasse seu limite, todas as interrupções, inclusive programadas, podem ser expurgadas e desconsideradas no cálculo de DEC e FEC. 


\subsubsection{1}

\section{Índices de Continuidade Individual}

Cada consumidor tem seus próprios índices de continuidade individuais que medem a qualidade da energia recebida. A qualidade da oferta desta energia está associada ao fornecimento individual, independente da qualidade dos demais clientes vizinhos. Os índices de continuidade individuais contribuem para a regulação da qualidade, pois tratam do problema da qualidade de energia recebida pelo consumidor. A energia elétrica é um produto de consumo que tem que ter as mesmas garantias de qualidade, confiabilidade e satisfação para o cliente como qualquer outro produto de mercado.

Os índices individuais, apurados para cada unidade consumidora, são [55]:

i) DIC: Duração de Interrupção Individual por Unidade Consumidora ou por Ponto de Conexão, conforme definido em (2.17) a seguir:

$$
\mathrm{DIC}=\sum_{i=1}^{n} t(i)
$$

ii) FIC: Frequência de Interrupção Individual por Unidade Consumidora ou por Ponto de Conexão, conforme definido em (2.18) a seguir:

$$
\mathrm{FIC}=n
$$

iii) DMIC: Duração Máxima de Interrupção Contínua por unidade consumidora ou ponto de conexão, conforme definido em (2.19) a seguir:

$$
\operatorname{DMIC}=t_{\text {máx }}(i)
$$

iv) DICRI: Duração de Interrupção Individual ocorrida em dia crítico por unidade consumidora ou ponto de conexão, conforme definido em (2.20) a seguir: 


$$
\text { DICRI }=t_{\text {crítico }}
$$

onde: $i$ = índice de interrupção da unidade consumidora no período de apuração, variando de 1 a $n ; n=$ número de interrupções da unidade consumidora considerada no período de apuração; $t(i)=$ tempo de duração da interrupção $i$ da unidade consumidora considerada ou ponto de conexão no período de apuração; $t_{\operatorname{máx}}(i)=$ valor correspondente ao tempo da máxima duração de interrupção contínua $i$, no período de apuração, verificada na unidade consumidora considerada, $t_{\text {crítico }}=$ duração da interrupção ocorrida em dia crítico, expresso em horas e centésimos de horas [55].

\subsubsection{2}

\section{Índices de Continuidade Coletiva}

Além dos indicadores individuais, definem-se para um determinado período os indicadores coletivos [55]. Esses indicadores de qualidade estão expressos por meio de percentual considerando o tempo médio de continuidade do fornecimento de energia em relação ao conjunto de consumidores. Por meio de uma média ponderada das faltas do sistema são localizados e convertidos os índices individuais dos clientes que possam ter sido afetados. Vale ressaltar que estes índices não refletem a qualidade da energia fornecida para cada consumidor, mas indicam o estado médio da qualidade de fornecimento do conjunto considerado. Em suma, pode haver clientes em uma região com índices de confiabilidade de boa qualidade e que tenha uma má qualidade de fornecimento. A qualidade de energia é mensurada por:

i) DEC: Duração Equivalente de Interrupção por Unidade Consumidora (corresponde ao índice SAIDI) é o intervalo de tempo no qual, em média, no período de observação, em cada unidade consumidora do conjunto considerado, ocorreu descontinuidade da distribuição de energia elétrica, calculado conforme equação (2.21):

$$
\mathrm{DEC}=\frac{\sum_{i=1}^{\mathrm{Cc}} \mathrm{DIC}(i)}{\mathrm{Cc}}
$$


ii) FEC: Frequência Equivalente de Interrupção por Unidade Consumidora (corresponde ao SAIFI) é o número de interrupções ocorridas, em média, no período de observação, em cada unidade consumidora do conjunto considerado, calculado conforme equação (2.22):

$$
\mathrm{FEC}=\frac{\sum_{i=1}^{\mathrm{Cc}} \mathrm{FIC}(i)}{\mathrm{Cc}}
$$

onde $\mathrm{Cc}=$ número total de unidades consumidoras faturadas do conjunto no período de apuração, atendidas em baixa ou média tensão.

Com o objetivo de mensurar o grau de impacto no DEC, o Cliente-HoraInterrompido (CHI) foi utilizado na presente dissertação e será discutido a seguir.

\subsubsection{3}

\section{Cliente Hora-Interrompido}

O $\mathrm{CHI}$ equivale ao número de clientes interrompidos associados ao equipamento de proteção $j$ que atua nos casos de falhas ou desligamentos programados para manutenção, no tempo $(t)$ de interrupção $i$ no período de apuração observado.

$$
\begin{gathered}
\mathrm{CHI}_{j}(i)=C_{j} \times t(i), \quad j=1, N_{E P} \\
N_{E P}=N_{D J}+N_{R D}+N_{S L}+N_{C F}+N_{T I}+N_{Z N A}
\end{gathered}
$$

onde $C$ equivale ao número de clientes interrompidos associados ao equipamento $j$, com $j=1, N_{E P}$, sendo $N_{E P}$ o número de equipamentos de proteção que existe no circuito de distribuição, $N_{D J}$ refere-se ao número de disjuntores, $N_{R D}$, religadores, $N_{S L}$, seccionalizadores, $N_{C F}$, chave-fusível, $N_{T I}$, transformador de isolamento, $N_{Z N A}$, transformador de distribuição. 
Os equipamentos de proteção são alocados na rede de forma estratégica para reduzir o número de clientes interrompidos em caso de falhas ou de manutenções programadas.

\section{5 \\ Conclusões}

Este capítulo apresentou uma visão geral dos conceitos sobre confiabilidade do sistema elétrico de potência. Após a privatização de grande parte das empresas distribuidoras, surgiu a necessidade de órgãos reguladores para o estabelecimento de novas regras para a prestação dos serviços públicos de fornecimento de energia aos consumidores finais. Com isso, no Brasil, foram estabelecidos limites por conjunto elétrico, e caso as distribuidoras ultrapassem esses limites, devem ser pagas multas ao órgão regulador e compensações financeiras ao cliente. Desta forma, o Brasil segue a tendência do setor elétrico mundial, onde também há um acompanhamento dos índices de continuidade e energia não suprida.

As novas regras estabelecidas pelos órgãos reguladores são baseadas em índices ou indicadores de desempenho que, associados com a disputa no mercado entre as concessionárias, fazem com que cada vez mais se invista em manutenções e melhorias na rede para garantir a redução de taxa de falhas dos equipamentos e menor tempo de interrupção.

Portanto, a probabilidade de um sistema atender seus consumidores, de forma contínua e adequada, está diretamente relacionada ao investimento na rede e com a manutenção dada. Contudo, grandes investimentos têm por consequência, custos elevados e baixos investimentos podem resultar em um sistema vulnerável às falhas. A confiabilidade do sistema e a assertividade nas atividades, portanto, são os pilares numa tomada de decisão. O desafio é então, encontrar o ponto ideal entre o menor custo e a maior confiabilidade possível.

A execução dos serviços de manutenção muitas vezes está vulnerável a orçamentos limitados, levando técnicos ou responsáveis pela atividade, escolherem quais serviços, dentre todos identificados em campo, serão realizados. 
A partir da necessidade da existência de uma forma inteligente de priorizar os serviços a serem realizados, no próximo capítulo será apresentada uma metodologia para eleger os pontos críticos de um alimentador, ou seja, os equipamentos e seus respectivos trechos ou segmentos que necessitam de manutenção com prioridade já que possuem maior participação nos indicadores de continuidade, tais como DEC e FEC, além de serem responsáveis por gerar compensações financeiras aos clientes. 


\section{3 \\ Planejamento da Manutenção via Matriz de Risco}

\section{1 Introdução}

No capítulo anterior foram tratados os índices que mensuram a qualidade do fornecimento de energia prestada pelas concessionárias aos consumidores. Os indicadores e os índices são projetados para simplificar a informação sobre o desempenho dos sistemas elétricos e indicar os pontos de melhoria ou piora em relação à visão histórica. São através dessas indicações que são tomadas as decisões de manutenção e planejamento das redes elétricas.

Sabe-se que a confiabilidade do sistema elétrico é, em princípio, "proporcional" aos investimentos em manutenção na rede. Cada distribuidora tem um orçamento disponibilizado para manutenção. Entretanto, quanto maior o investimento, maior será a tarifa.

A aplicação dos recursos destinados à melhoria do sistema de distribuição necessita de suporte à tomada de decisões por parte do planejador. Este suporte deve ser suprido através de ferramentas computacionais ou modelos matemáticos onde é possível indicar as variáveis do sistema.

Sendo assim, é importante o desenvolvimento de ferramentas computacionais para auxiliar o planejamento de distribuição. A experiência do planejador deve ser agregada a essas ferramentas, integrando condições econômicas, redução de perdas elétricas e qualidade no fornecimento dos serviços.

Por isso, uma metodologia que identifica os equipamentos e trechos que correspondem a pontos críticos e de maior impacto em uma rede de distribuição de energia será apresentada neste capítulo. 


\section{2 Serviços de Manutenção}

A manutenção é entendida pelas organizações por meio da abordagem que tenta evitar falhas ao cuidar de suas instalações [56]. Para empresas de pequeno, médio e grande porte, os equipamentos e processos têm que operar em ponto "ótimo", e essa condição requer prudência, tomada de decisões e uma sintonia entre pessoal, máquinas e materiais [57].

Todas as concessionárias apresentam um processo produtivo onde a melhora na operação pode influenciar positivamente na competitividade, ou seja, melhorar a sua operação junto ao mercado. Para que seja possível obter um bom resultado, ou seja, melhoria do processo, é preciso criar parâmetros e conhecer a situação do sistema e sua eficiência.

Quando a manutenção é considerada atuante, os seguintes benefícios são atingidos [56]:

- Segurança melhorada - diminui o risco às pessoas que atuam no ambiente;

- Confiabilidade aumentada - menos tempo perdido com conserto;

- Qualidade maior - equipamentos em melhor desempenho;

- Custos de operação mais baixos - alguns elementos de tecnologia funcionam melhor quando recebem manutenção regularmente;

- Tempo de vida mais longo - prolongar a vida efetiva das instalações;

- Valor final mais baixo - instalações bem mantidas propiciam vendas de segunda mão para o mercado.

A programação de uma boa manutenção e sua organização contribuem, portanto, para melhoria do processo que vai desde o aumento da produtividade até a redução de custos.

Existem várias formas de realizar a manutenção no sistema e que estão relacionadas ao tempo de uso dos equipamentos. São elas: manutenção corretiva (que pode ser em caráter emergencial ou não), manutenção preventiva, manutenção preditiva e manutenção detectiva [58]. 
A manutenção corretiva pode ser planejada ou não. É caracterizada pela atuação das equipes na ocorrência de falhas ou de desempenhos inferiores ao esperado. Nesse caso, não há tempo para o planejamento do serviço: é a correção da falha a fim de evitar outras consequências [58]. Geralmente o custo dela é menor quando comparada a uma manutenção preventiva, porém pode causar grandes perdas por interrupção do fornecimento de energia elétrica. Há casos em que a correção depende de decisão gerencial, seja em função de acompanhamento preditivo ou, seja pela decisão de operar até a inoperância do equipamento. Ainda pode ser originada por fatores como: aspectos ligados à segurança, garantia de ferramental e peças sobressalentes.

A manutenção preventiva faz referência à atuação realizada de maneira a reduzir, evitar a falha ou a queda no desempenho do equipamento, obedecendo a um plano de manutenção previamente elaborado, baseado em intervalos definidos de tempo. Com o uso de dados estatísticos de arquivos ou históricos disponíveis nas empresas, é possível estimar com alguma expectativa o tempo em que ocorrerá a falha. Essa estimativa trata de uma probabilidade de ocorrência da falha. É possível ainda, reduzir a probabilidade de falhas pelo fato de a manutenção ser programada com antecedência. É um trabalho sistemático para evitar a ocorrência de falhas procurando a sua prevenção, mantendo um controle contínuo sobre o equipamento [59].

A manutenção preditiva é baseada na tentativa de definir o estado futuro de um equipamento ou sistema, por meio dos dados históricos verificando e analisando a tendência de variáveis do equipamento. Os dados coletados são baseados em medições em campo de temperatura, análise físico-química de óleos e ensaios por termografia. Contudo, estes dados não permitem um diagnóstico preciso, pois trabalha no contexto de uma avaliação probabilística [60]. Em suma, é a execução da manutenção no momento adequado, antes que o equipamento apresente a falha.

Manutenção detectiva é um tipo de manutenção efetuada em sistemas de proteção buscando detectar falhas ocultas ou não perceptíveis às equipes de operação e manutenção [58].

A identificação da necessidade da manutenção em redes de distribuição de energia se inicia, geralmente, a partir de uma inspeção visual realizada por técnicos de manutenção. Nesta inspeção, são identificados através da percepção do 
funcionário, os serviços a serem executados, tais como: poda de árvores, substituição ou reparo de equipamentos, estruturas, rede, componentes, dentre outros. A execução desses serviços muitas vezes está vulnerável a orçamentos limitados, levando aos técnicos ou responsáveis pela atividade, escolherem quais serviços, dentre todos os identificados em campo, serão realizados.

Portanto, a partir da necessidade da existência de uma forma inteligente de priorizar os serviços a serem realizados, será apresentada na sequência, uma metodologia para eleger os pontos críticos de um alimentador, ou seja, os equipamentos e seus respectivos trechos que necessitam de manutenção com prioridade, já que possuem maior participação nos indicadores de continuidade, tais como DEC e FEC, além de serem responsáveis por gerarem compensações financeiras aos clientes.

\section{3 Metodologia Proposta}

A avaliação dos fatores de risco é uma das etapas de qualquer processo de gerenciamento. Uma das formas de identificar o fator de risco é utilizando o conceito de Matriz de Risco [50], [51].

A implantação do gerenciamento de risco traz vários benefícios para o processo de avaliação de reincidência de falhas:

i) Mostra de forma assertiva os trechos vulneráveis, cujo objetivo é a redução da reincidência, redução dos indicadores de continuidade e, consequentemente, a otimização dos recursos que serão redirecionados à execução de serviços em trechos prioritários, se comparados a trechos que não causam impactos tão significativos nos indicadores da concessionária;

ii) Fomenta o processo de melhoria contínua, estimulando as equipes na busca das melhores práticas, visando o menor custo global atrelado à eliminação do risco, promovendo a maior transparência ao informar os 
riscos aos quais a organização está sujeita, as políticas adotadas para sua mitigação, bem como a eficácia das mesmas;

iii) Melhora os padrões de gerenciamento, além de introduzir uma uniformidade conceitual em todos os níveis.

Neste estudo, a metodologia proposta usa uma matriz de risco, que apresenta em seus eixos escalas de reincidências de ocorrências de interrupção de energia (maiores que 3 minutos), bem como os impactos nos indicadores de continuidade.

A classificação dos níveis da matriz de risco (eminente, crítico, alto, médio e baixo) é feita de acordo com o histórico de falhas dos alimentadores de uma determinada região, o tempo médio de atendimento e o máximo número de clientes interrompidos por atuação da principal proteção de cada rede de distribuição. Cada um dos fatores de risco identificado é avaliado qualitativamente, em termos de probabilidade e impacto, e posicionado na matriz, indicando o fator de risco, conforme Figura 3.1.

Combinando o nível de impacto com o nível de reincidência, tem-se o risco inerente. É através deste que será indicado qual trecho/equipamento deverá ser tratado prioritariamente. Através da visualização, a criticidade dos riscos é indicada por meio da visualização de cores.
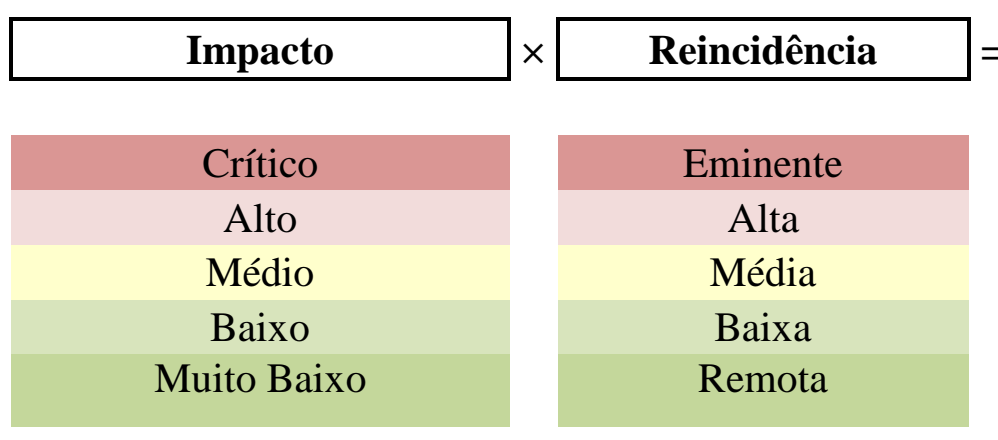
$=$ Risco Inerente

Figura 3.1 - Metodologia da Matriz de Risco.

Nesse contexto, a partir do resultado de impacto versus reincidência, é possível melhorar o direcionamento dos serviços de manutenção para os trechos 
que apresentam os piores resultados nos indicadores da empresa, ou seja, aqueles com risco inerente alto e crítico.

\subsection{1}

\section{Matriz de Risco}

A matriz de risco é uma ferramenta que permite mensurar, avaliar e ordenar os eventos de riscos que podem afetar o alcance dos objetivos do processo da unidade. Ela apresenta uma escala de probabilidade e impacto (matriz 5×5) e está posicionada em cinco regiões. Essas regiões caracterizam os níveis de riscos dimensionados em função do risco definido; ver [61].

Nesta dissertação, denomina-se o eixo de probabilidade de reincidência, que faz referência à quantidade de falhas no mesmo trecho e/ou equipamento de proteção. O eixo de impacto faz referência ao valor de $\mathrm{CHI}$ (definido no item 2.4.2.3).

Para cada eixo (probabilidade e impacto) é definido um nível, a saber: crítico, alto, médio, baixo e muito baixo. Cada nível será detalhado no item 3.3.2.

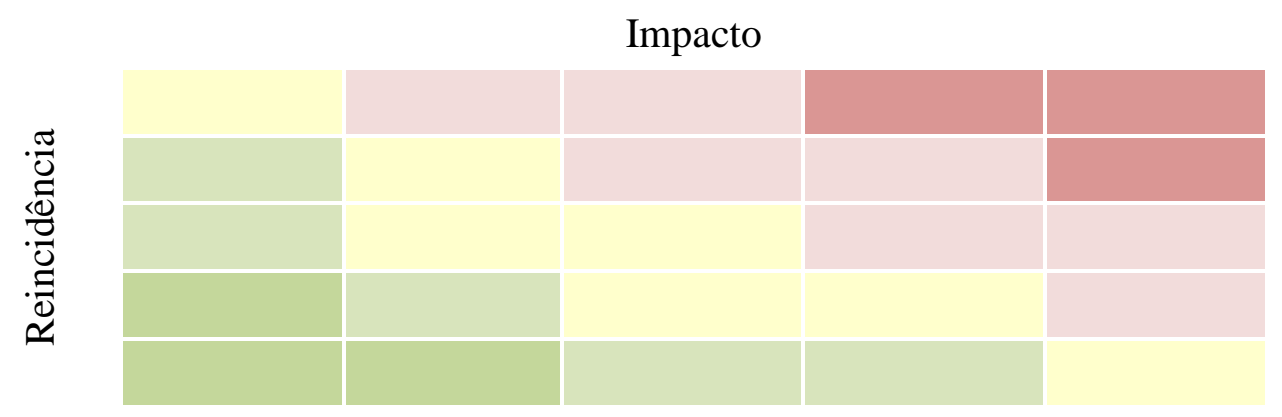

Figura 3.2 - Matriz de Risco.

A Figura 3.2 indica que quando combinados os níveis de impacto com os níveis de reincidência, o Risco Inerente é representado por cores. É através desse resultado que irão se definir as prioridades de atuação da manutenção dos piores trechos. 
O valor de CHI equivale ao Cliente-Hora-Interrompido para efeito na definição de níveis na matriz de risco, com base no histórico de falhas de um sistema de distribuição real.

A matriz de risco é construída então, atribuindo pesos às classes de reincidências e impacto de $\mathrm{CHI}$, definindo as classes de risco a partir da combinação dos dois eixos. O resultado é obtido através da multiplicação do "peso". Dessa forma, obtêm-se as regiões de classificação do risco, exemplificadas nas cores verde claro (impacto mínimo nos indicadores, com baixo comprometimento à prestação dos serviços), verde escuro (impacto baixo nos indicadores, com pouco comprometimento na prestação dos serviços), rosa (impacto alto nos indicadores, comprometendo significativamente a prestação dos serviços) e a cor vinho (impacto crítico, causando maior insatisfação dos clientes e ações de penalidades junto ao órgão regulador, por não prestar serviços de qualidade/continuidade). A região de atuação, portanto, é prioritariamente, a região vinho e na sequência a região cor de rosa.

Caso ocorra a indicação de mais de um equipamento em uma mesma região de risco, o critério a utilizar para prioridade, dentre esses, é a avaliação do maior valor de compensação financeira (expressa em reais que é somatório do valor de multas pagas para cada cliente em cada trecho do alimentador), a qual foi paga no período de um ano aos consumidores de acordo com o trecho indicado.

Para obter os Riscos, é necessário definir os níveis de cada eixo: reincidência e de impacto.

\subsection{2}

\section{Eixos de Reincidência e Impacto}

A escala de reincidência é associável às técnicas quantitativas ou ao histórico dos eventos. No exemplo a ser descrito nessa dissertação, foi verificado o histórico de ocorrências de alimentadores reais, onde após analisadas todas as falhas dos anos de 2014, 2015 e 2016, foi observado que a média de falhas dos equipamentos é da ordem de ocorrência 4 a 5 vezes ao ano.

Com isso, foi considerado o pior risco, para cada escala de reincidências, quando o equipamento de proteção atua, seja por defeito no trecho, ou seja, nele mesmo, cinco vezes. 
A escala de reincidências de ocorrências de falha é apresentada na Tabela 3.1, onde quanto maior o número de falhas, mais vulnerável o sistema está em relação à prestação do serviço de fornecimento de energia.

Tabela 3.1- Níveis e pesos para o eixo Reincidência.

\begin{tabular}{lcc}
\hline \hline Risco & Reincidência & Peso \\
\hline \hline 5. Eminente & $\geq 5$ & 5 \\
\hline 4. Alta & $>3,0 \mathrm{e} \leq 4,0$ & 4 \\
\hline 3. Média & $>2,0 \mathrm{e} \leq 3,0$ & 3 \\
\hline 2. Baixa & $>1,0 \mathrm{e} \leq 2,0$ & 2 \\
\hline 1. Remoto & $1,0 \leq$ & 1 \\
\hline \hline
\end{tabular}

A escala de impacto considera as consequências econômico-financeiras e as consequências estratégicas e operacionais de um dado evento de risco. Para análise do impacto nos indicadores de continuidade, foi utilizado o critério do pior cenário de interrupção de um alimentador com todos os clientes interrompidos no tempo médio de atendimento durante o período de um ano.

Dessa forma, o maior impacto por circuito é dado conforme a seguir:

$$
\mathrm{CHI}_{\text {máx }}=\mathrm{Cc} \times \mathrm{T}_{\mathrm{m}}
$$

onde: $\mathrm{CHI}_{\text {máx }}$ é o maior valor de $\mathrm{CHI}$ no período de um ano, expresso em horas e centésimos de horas; Cc é o número máximo de clientes interrompidos, $\mathrm{T}_{\mathrm{m}}$ é o tempo médio de restauração do fornecimento de energia das ocorrências de atendimentos originados por defeitos no sistema de distribuição referente ao alimentador analisado no período de um ano, expresso em horas.

A partir do histórico dos anos de 2014, 2015 e 2016 e após definido o pior cenário, definem-se os níveis de impacto de acordo com a Tabela 3.2. 
Tabela 3.2 - Níveis e pesos para o eixo de Impacto.

\begin{tabular}{lccc}
\hline \hline Risco & Impacto CHI máx $(\%)$ & Peso & CHI \\
\hline \hline 5. Crítico & $>13,0$ & 5 & $>1500$ \\
\hline 4. Alto & $>8,0 \mathrm{e} \leq 13,0$ & 4 & 1200 \\
\hline 3. Médio & $>5,0 \mathrm{e} \leq 8,0$ & 3 & 900 \\
\hline 2. Baixo & $>3,0 \mathrm{e} \leq 5,0$ & 2 & 600 \\
\hline 1. Mínimo & $3,0 \leq$ & 1 & 300 \\
\hline \hline
\end{tabular}

Após a definição dos níveis, o histórico de ocorrências de falhas em uma rede de distribuição é processado em uma planilha, e assim, os equipamentos são alocados na matriz de risco para a identificação dos trechos que deverão ser tratados com maior atenção e prioridade.

\subsection{3}

\section{Procedimentos}

A metodologia utilizada nessa dissertação é dividida em cinco etapas:

i) Identificação dos riscos: classificar os riscos;

ii) Avaliação dos riscos: analisar a reincidência, impacto no $\mathrm{CHI}$ e alocação de equipamentos no mapa de risco;

iii) Tratamento dos riscos: determinar o posicionamento frente aos riscos;

iv) Plano de ação: definir responsáveis, prazos e entrega dos tratamentos dados aos riscos;

v) Monitoramento: monitorar os indicadores e resultados após dada ação aos piores níveis de risco.

Para cada equipamento, quando combinado o impacto $\mathrm{CHI}$ com a quantidade de falhas, é indicado qual o nível de risco o equipamento se encontra e definida a posição na matriz.

Para os riscos críticos e eminentes, ações de manutenção devem ser tomadas o mais breve possível. 
Para identificação dos trechos e/ou equipamentos com os piores níveis de risco, deve-se utilizar o histórico de falhas da rede, onde o trecho é indicado através do equipamento de proteção que atuou.

Estes por sua vez, tem a finalidade de isolar o curto-circuito o mais próximo possível do ponto em que foi originado, para que não danifique os demais equipamentos do alimentador. Além disso, são alocados em pontos estratégicos para que ocorra a seletividade, ou seja, isolar somente o ponto atingido pelo defeito e manter a continuidade de energia para as demais cargas conectadas ao sistema.

\subsection{4}

\section{Descrição do Funcionamento da Metodologia}

A matriz de risco com os resultados é construída em um arquivo Excel $(x l s m)$. Neste, os níveis já estarão pré-determinados. Através de uma programação em VBA (Virtual Basic for Applications), o histórico das ocorrências de falhas e compensação financeira dos alimentadores é registrado. A consulta é automática no sistema de gestão de distribuição da concessionária.

Após a leitura do histórico de falhas, a programação seleciona todos os equipamentos de proteção que atuaram em caso de defeitos ou manutenções emergenciais. Ela também faz o cálculo de reincidência destes defeitos, verifica o tempo de restauração de cada trecho e calcula o CHI.

Após o resultado dessas contagens, a macro indica, em uma nova aba do arquivo em Excel, a relação dos equipamentos com o valor de reincidência, denominada Frequência Simples Sustentável (FSS), impacto no CHI e número de clientes (CI), conforme indicado na Tabela 3.3.

Tabela 3.3 - Relação dos equipamentos com reincidências e indicadores.

\begin{tabular}{|l|c|c|c|c|c|c|}
\hline \multicolumn{1}{|c|}{ Dispositivo } & SE & Alimentador & Linha & FSS & CHI & CI \\
\hline CF-544584 & FTL & LDA COTIARA & LDA COTIARA & 2 & 0 & 0 \\
\hline CF-544771 & FTL & LDA COTIARA & LDA COTIARA & 2 & 115 & 63 \\
\hline CF-544837 & FTL & LDA COTIARA & LDA COTIARA & 1 & 13 & 5 \\
\hline CF-545027 & FTL & LDA COTIARA & LDA COTIARA & 2 & 0 & 2 \\
\hline CF-545028 & FTL & LDA COTIARA & LDA COTIARA & 1 & 0 & 0 \\
\hline
\end{tabular}


Posteriormente, é feita uma relação dos níveis de impacto e reincidência previamente definidos por testes executados de acordo com o histórico de falhas (2014 a 2016) e compensação financeira. Em uma nova aba, tem-se a relação dos pesos e o nível de prioridade por equipamento conforme indicado na Figura 3.3.

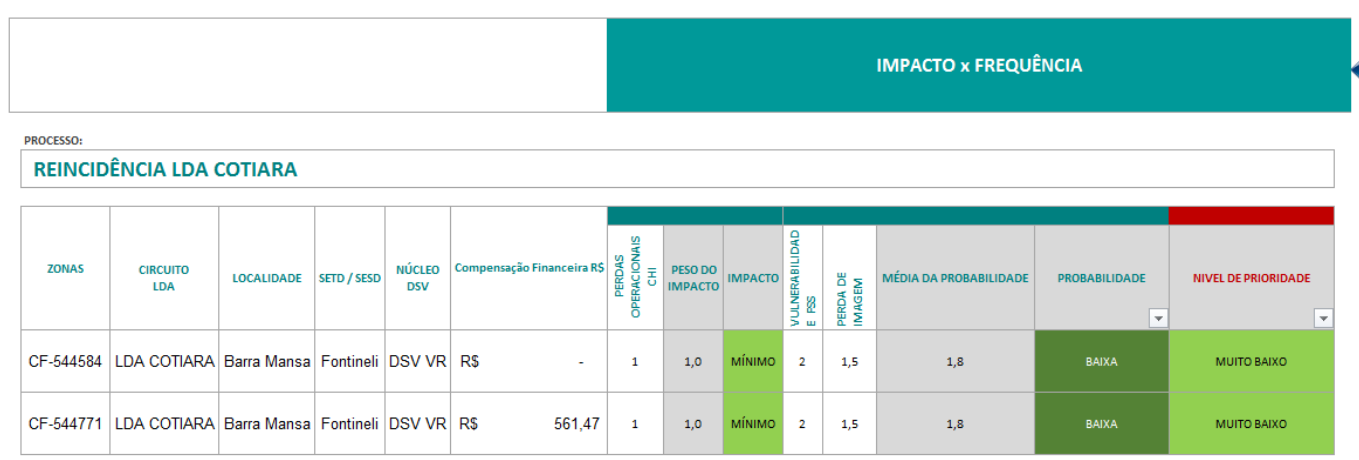

Figura 3.3 - Relação dos equipamentos e níveis de prioridade.

Quando houver mais de um equipamento para um mesmo nível de risco, o de maior prioridade será aquele de maior compensação financeira paga aos clientes. Esse valor, expresso em reais, é indicado na aba conforme Figura 3.3.

A partir dessa relação de Impacto x Vulnerabilidade x Probabilidade e Nível de prioridade, os equipamentos são alocados na Matriz de Risco, conforme indicado na Figura 3.4. Os números representados em cada quadrante representa a quantidade de equipamentos/trechos que estão em um mesmo nível de risco.

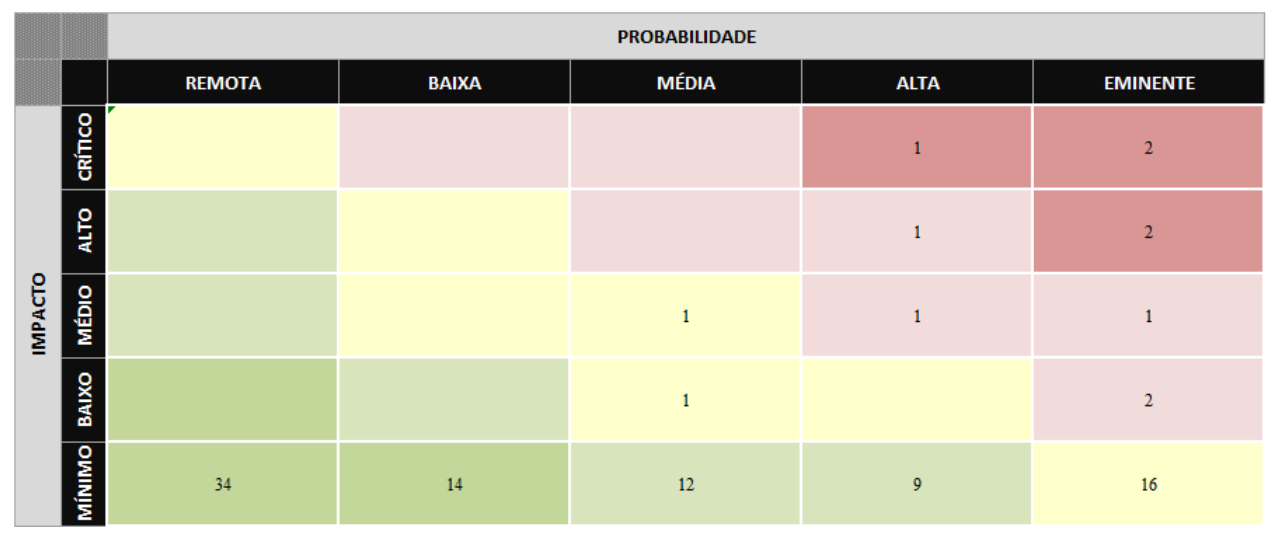

Figura 3.4 - Matriz de Risco. 
Após identificar os trechos de maiores impactos nos indicadores de fornecimento de energia, o técnico de manutenção deverá fazer uma inspeção na rede de distribuição. Para inspeção, pode se utilizar, além do meio visual, os drones e o termovisor ${ }^{4}$.

Na sequência, após a verificação em campo, cria-se um plano de ação no mesmo arquivo, indicando o prazo e o serviço a ser realizado para redução dos indicadores nos trechos críticos e eminentes; conforme Figura 3.5.

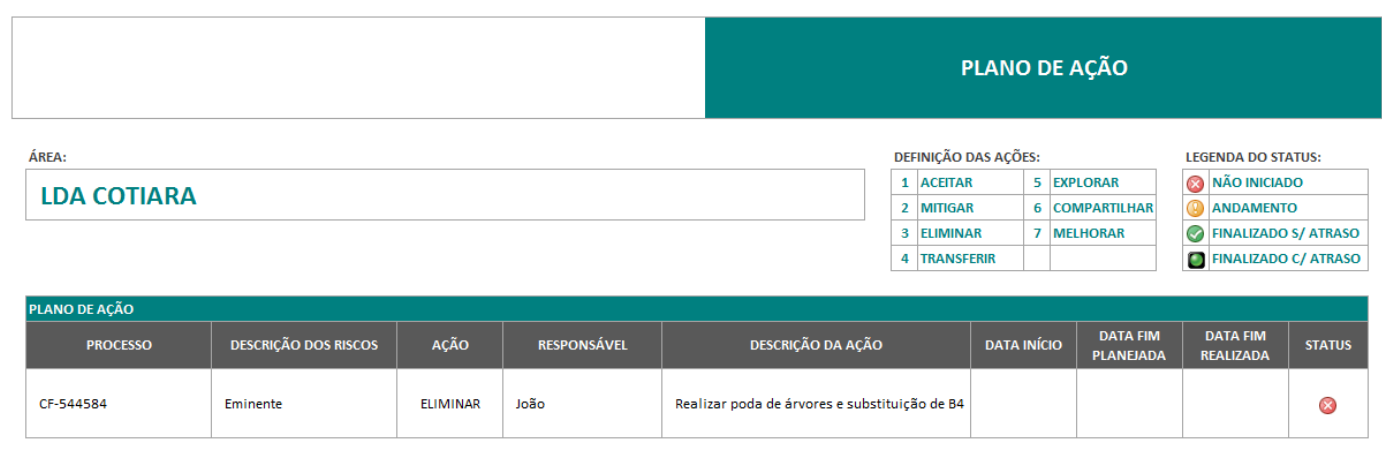

Figura 3.5 - Plano de ação.

Após executar as ações de manutenção, é necessário monitorar o sistema elétrico de distribuição para acompanhar o desempenho do alimentador.

A vantagem dessa metodologia é que ela pode ser aplicada em qualquer rede de distribuição desde que seja possível obter o histórico dos alimentadores e os valores de DIC e FIC pagos aos consumidores.

\section{4 \\ Conclusões}

Este capítulo apresentou o detalhamento da metodologia proposta aplicada em um sistema elétrico de distribuição de energia.

O gerenciamento de riscos é um fator fundamental para o planejamento estratégico de qualquer empresa e tem como objetivo identificar e analisar os riscos

4 Equipamento composto por uma câmera que identifica pontos elétricos com altas temperaturas. 
que podem estar sujeitos. O objetivo do estudo desses riscos é minimizar ou mesmo eliminar a possibilidade terem um impacto negativo sobre os indicadores e satisfação dos clientes.

O mapa de risco indica, de forma simples, através de cores os níveis de prioridade. A partir dessa indicação é possível direcionar o recurso financeiro e de manutenção para as áreas de maior impacto na rede de distribuição, uma vez que, geralmente o orçamento disponibilizado para manutenções é limitado.

Em função do orçamento limitado para manutenções e frente à necessidade de atender as metas estabelecidas, o planejamento eficiente de manutenção é extremamente necessário com vistas a mitigar as interrupções e atender a oferta e o fornecimento de energia.

A partir do histórico de falhas e de compensações financeiras de um alimentador, obtêm-se os trechos de maior impacto. É necessária a verificação em campo, através de inspeções para definir o prazo de programação dos serviços a serem realizados para melhoria do desempenho da rede. Então, a experiência do técnico é agregada à ferramenta.

Um plano de ação deve ser criado a partir dos níveis críticos indicado e após o serviço ser executado. E após a elaboração do plano os indicadores desse sistema de distribuição de energia devem ser monitorados.

Para validar a proposta metodológica, foi utilizado um sistema-teste real de uma rede de distribuição da concessionária de energia da região Médio Vale do Paraíba. Os resultados podem ser verificados no próximo capítulo. 


\section{4 \\ Aplicação da Metodologia Proposta}

\section{1}

\section{Introdução}

No capítulo anterior foi tratada a metodologia para identificar os equipamentos ou trechos prioritários de uma rede de distribuição para auxiliar o técnico de manutenção no planejamento de recursos financeiros e de mão de obra.

A identificação da necessidade de manutenção em redes de distribuição se inicia geralmente a partir de inspeções visuais realizadas por técnicos. É através da percepção desses funcionários que são indicados os serviços a serem executados, tais como podas, substituição de redes e estruturas.

Em uma rede de distribuição, há vários trechos que sofrem interrupções de energia. Quanto maior a reincidência dessas interrupções e maior o tempo de restabelecimento do fornecimento de energia para os clientes conectados a esses trechos, maior será o valor de compensação financeira paga a esses consumidores, maior será o indicador de continuidade e maiores serão as penalidades aplicadas à concessionária.

Neste capítulo, serão apresentados os resultados em dois sistemas-testes reais de uma rede de distribuição de energia de uma concessionária da região Sul Fluminense. Esses sistemas são responsáveis pelo fornecimento de energia elétrica na região de maiores concentrações de carga no município de Barra Mansa, localizado na região no Médio Vale do Paraíba.

\section{2}

\section{Planejamento da Manutenção}

A organização dos setores de manutenção de uma forma geral reflete os estágios de desenvolvimento industrial do país [62]. A manutenção dos sistemas 
elétricos de potência por sua vez, é importante para amenizar as exigências do mercado e das condições operacionais. A partir do histórico de dados e informações sobre desempenho do sistema, é possível criar meios para análises críticas e observações sobre o fornecimento de energia.

Cabe ao setor de manutenção gerar condições operacionais para os equipamentos e rede elétrica, visando atingir objetivos e metas estipuladas pelo órgão regulador, e assim, fornecer aos consumidores boa qualidade, eficiência e segurança no sistema elétrico de distribuição.

Na rede de distribuição de energia elétrica, são utilizados cabos de condução de energia, transformadores e equipamentos de proteção. Para todos esses, é necessária uma manutenção eficiente para manter a continuidade do sistema.

Todavia, as manutenções em sistemas elétricos requerem de seus profissionais um alto nível de conhecimento das atividades devido à periculosidade. Por isso, constantes pesquisas são realizadas buscando novas formas de executar os serviços com maior segurança. Normalmente, ao realizar uma intervenção no sistema elétrico, interrompe-se o fornecimento de energia por um período de tempo, e por essa razão é dito que está trabalhando com "linha morta" devido ao fato do circuito estar com a energia interrompida. Entretanto, os desligamentos impactam nos indicadores de continuidade DEC e FEC e contribuem negativamente na apuração de metas.

Para melhorar os indicadores por interrupções programadas, as concessionárias vêm se preocupando em introduzir técnicas que permitam trabalhar com a linha energizada, chamada também de "linha viva". Essas atividades passam a ser uma forma de reduzir os desligamentos por serviços programados, evitando trazer maiores prejuízos à concessionária e aos consumidores. Porém, por ser um serviço oneroso e caro (a mão de obra tem que ser mais qualificada por trabalhar com a linha energizada), é necessário atender alguns requisitos como: controle de custo de manutenção dos equipamentos e das redes.

Para que o monitoramento das redes de distribuição seja realizado com eficiência satisfatória, é necessário ter um acompanhamento gerencial para a sistematização das atividades de manutenção, tais como: coleta dos dados de interrupções constantemente, identificação das diversas formas de interferência no 
sistema elétrico definindo periodicidade, levando em consideração a topologia da região e épocas do ano (geralmente no verão ocorrem maiores defeitos qualitativamente e em quantidade - devido a sobrecargas no sistema elétrico e chuvas). Assim, deve-se realizar o acompanhamento do comportamento operacional dos dispositivos de proteção com o objetivo de investigar seu comportamento nos indicadores de interrupção ou por falhas por mau dimensionamento. A classificação dos consumidores mais importantes e a vulnerabilidade destes também devem ser acompanhadas.

É necessário ter um suporte técnico capaz de coordenar os critérios do planejamento e monitorar o desempenho das linhas do sistema elétrico pósmanutenção.

A execução, de modo sistemático, de um adequado programa de manutenção das instalações elétricas está inserida no contexto da filosofia de conservação de energia elétrica, visto que sua ausência implica aumento de perdas térmicas, custos adicionais imprevistos em virtude da incidência de defeitos nas instalações, maior consumo e maior probabilidade de ocorrência de incêndios. Portanto, é preciso ter uma boa gestão e atuação da manutenção nos sistemas elétricos [63].

No fornecimento de energia em áreas rurais, onde as redes de distribuição são longas e ramificadas, a instalação de equipamentos de proteção como seccionalizadores e religadores auxilia na gestão de manutenção, pois esses equipamentos são telecomandados, sendo possível verificar em tempo real, quando há defeitos a jusante ${ }^{5}$ destes. Dessa forma, é possível garantir o restabelecimento do fornecimento de energia com maior rapidez e auxiliar nas manutenções que poderão ser realizadas nas proximidades.

Um planejamento de manutenção aplicado em um sistema-teste real será mostrado na sequência.

\footnotetext{
${ }^{5}$ Remete para o local situado depois de um determinado fato, objeto ou situação.
} 


\section{3 \\ Sistema-Teste}

O sistema-teste apresentado nesta seção, denominado LDA Cotiara, pertence à concessionária da região Médio Vale do Paraíba Fluminense, localizado no município de Barra Mansa. Essa rede de distribuição é responsável pela maior demanda de carga do município.

É uma linha de distribuição aérea (LDA) com sistema radial com recurso. Originada em uma subestação de transmissão e distribuição (SETD) que recebe duas linhas de transmissão de $138 \mathrm{kV}$ e abaixa para 14 linhas de $13.8 \mathrm{kV}$ em nível de distribuição através de três transformadores com capacidade de 20 MVA cada.

A Figura 4.1 representa o sistema elétrico nessa SETD. Os retângulos destacados na cor laranja representam os disjuntores de cada rede de distribuição. Além disso, essa subestação conta com mais 9 opções de disjuntores (retângulos cinza) para manobras entre os barramentos para remanejamento de cargas entre os transformadores quando necessário.

Os disjuntores destacados na cor cinza com contorno azul, além de atuar para proteção das seções do barramento, atuam diretamente para proteger os transformadores em caso de falhas nas próprias seções. A SETD também conta com proteção de barramento dos transformadores para altas correntes, representados por WXO e indicados pela seta verde.

Há também, dois disjuntores gerais, destacados na cor marrom, que atuam na proteção do barramento principal.

Nota-se que há dois disjuntores vagos, indicados com o contorno na cor roxa, a estes não foi conectada nenhuma carga, mas é possível acrescentar duas linhas de distribuição se necessário.

A linha amarela representa o caminho do Transformador 2 até o disjuntor da LDA Cotiara, a qual será estudada nesta sessão.

O diagrama original da SETD com o detalhe completo de todos os componentes pode ser visto em Apêndice. 


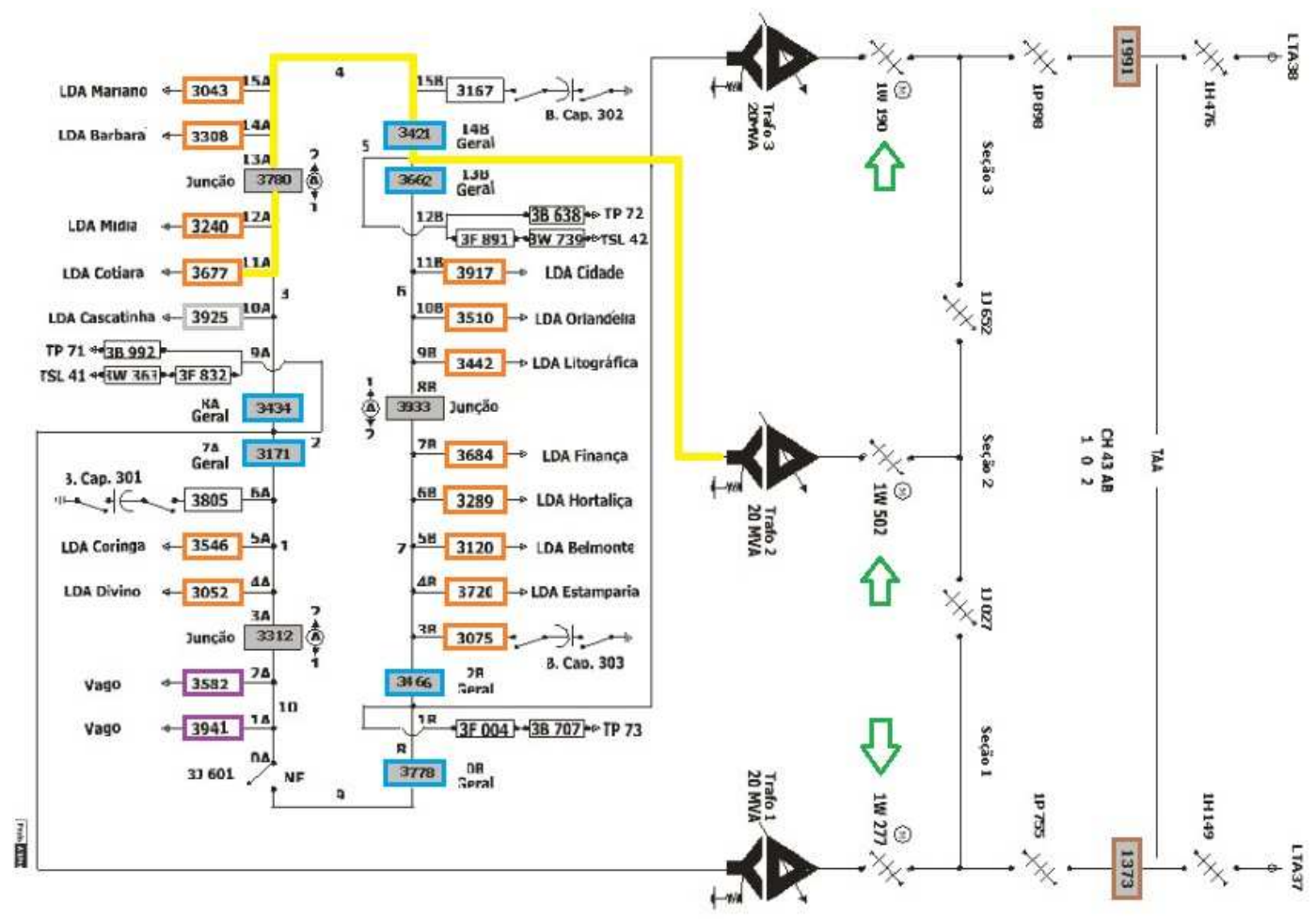

Figura 4.1 - SETD: destaque LDA Cotiara [65].

A linha de distribuição segue a configuração representada na Figura 4.2.

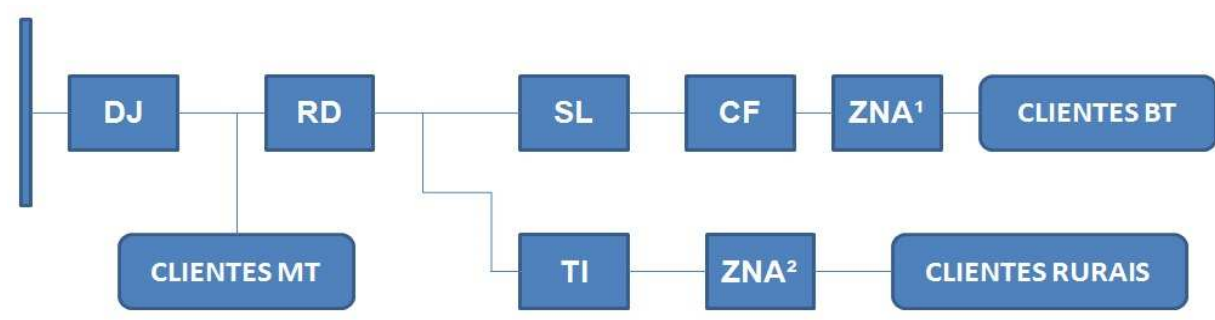

Figura 4.2 - Configuração da rede de distribuição.

Este alimentador possui: $N_{E P}=98$, onde, $N_{D J}=1, N_{R D}=2, N_{S L}=3, N_{C F}=16$ e $N_{Z N A}=76$ sendo responsável pelo fornecimento de energia a 3412 clientes (grandes clientes mais clientes residenciais).

O diagrama da linha de distribuição, com todos os equipamentos detalhados, encontra-se em Apêndice. 


\subsection{2}

\section{Resultados}

A partir do histórico de ocorrências de falhas, análise de reincidências e valor de CHI, os equipamentos de proteção que atuaram, por falhas nos mesmos, e/ou nos trechos, são alocados de acordo com seu nível de criticidade no mapa de risco e posteriormente são identificados para tratativa de manutenção.

$\mathrm{Na}$ metodologia proposta, para identificação do risco, tem-se que o alimentador possui 3412 clientes e o tempo médio de restauração é equivalente a 3,51 horas, considerando o histórico do ano de 2016.

Assim, o maior impacto no indicador de continuidade, apontado através do $\mathrm{CHI}_{\text {máx }}$ do circuito-teste, conforme (4.1), é:

$$
\mathrm{CHI}_{\text {máx }}=3.412 \times 3,51=11.976,12 \quad[\text { cliente } \times \mathrm{h}]
$$

Os níveis do eixo de reincidência são dispostos conforme a Tabela 3.1, o eixo do impacto com seus respectivos pesos são de acordo com a Tabela 3.2, a partir do $\mathrm{CHI}_{\text {máx }}$ que se encontra na Tabela 4.1.

Tabela 4.1 - Níveis de impacto do sistema teste.

\begin{tabular}{lccc}
\hline \hline Risco & Impacto CHImáx $(\%)$ & Peso & CHI \\
\hline \hline 5. Crítico & $>13,0$ & 5 & $>1500$ \\
\hline 4. Alto & $>8,0 \mathrm{e} \leq 13,0$ & 4 & 1200 \\
\hline 3. Médio & $>5,0 \mathrm{e} \leq 8,0$ & 3 & 900 \\
\hline 2. Baixo & $>3,0 \mathrm{e} \leq 5,0$ & 2 & 600 \\
\hline 1. Mínimo & $3,0 \leq$ & 1 & 300 \\
\hline \hline
\end{tabular}

Para alocação dos equipamentos no mapa de risco, obteve-se o resultado apresentado na Figura 4.3 que indica nove (9) equipamentos/trechos, localizados na região de cor vinho e que apresentam os piores níveis de risco. Deverão ser realizadas as manutenções de forma mais breve possível, uma vez que estes foram alocados devido ao maior impacto nos indicadores. 


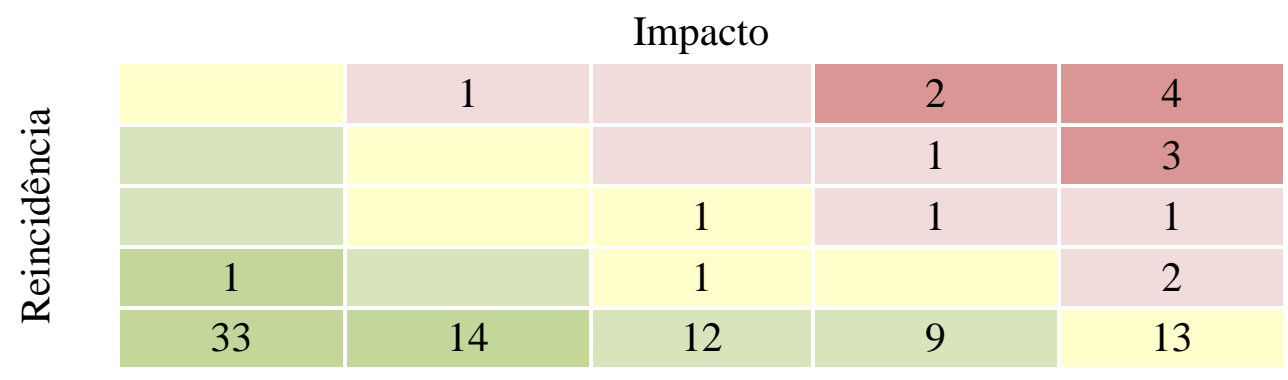

Figura 4.3 - Matriz de Risco do circuito teste.

Para o tratamento dos riscos, como critério de desempate, considera-se o trecho onde se pagou o maior valor de compensação financeira. Assim, os trechos em ordem de prioridade para manutenção podem ser expressos conforme a Tabela 4.2 .

Tabela 4.2 - Trechos e/ou equipamentos com risco inerente.

\begin{tabular}{lccc}
\hline \hline Equipamento/Trecho & Compensação Financeira (R\$) & $\begin{array}{c}\text { Nível } \\
\text { Reincidência }\end{array}$ & $\begin{array}{c}\text { Nível } \\
\text { Impacto }\end{array}$ \\
\hline \hline RD-544805 & $18.898,25$ & Eminente & Crítico \\
\hline CF-7892 & $5.084,27$ & Eminente & Crítico \\
\hline SL-533745 & $3.522,99$ & Eminente & Crítico \\
\hline SL-533747 & $2.624,97$ & Alto & Crítico \\
\hline CF-545036 & $2.146,57$ & Alto & Crítico \\
\hline ZNA21396 & $2.132,03$ & Eminente & Alto \\
\hline ZNA110407 & $1.729,66$ & Eminente & Alto \\
\hline ZNA19433 & 703,65 & Eminente & Crítico \\
\hline ZNA12189 & 148,77 & Eminente & Alto \\
\hline \hline
\end{tabular}

A partir daí, cria-se um plano de ação para a tratativa dos trechos identificados como piores, tendo como referência as causas dos desarmes desses equipamentos.

Na Tabela 4.2, verifica-se o RD-544805, religador de trecho, onde o mesmo atuou por falhas causadas por fenômenos naturais como temporal e por falhas ocasionadas por galhos de árvore na rede. 
O equipamento CF-7892 atuou por falhas na rede por temporal e galhos de árvore.

O SL-546745 atuou também por causas como temporal, galho de árvore e teve ainda uma ocorrência por ação de terceiros (não gerenciáveis pela concessionária).

O equipamento SL-533747 atuou por galho de árvore e por falha em um equipamento de seccionamento manual: GLV (grampo de linha viva).

A CF-545036 atuou por galhos de árvore sobre a rede.

Os transformadores de distribuição: ZNA21396, ZNA110407, ZNA19433 e ZNA12189, desarmaram por falhas no próprio equipamento, por fenômenos naturais (e.g., chuvas e ventos) e por ações de terceiros.

Após definidos os equipamentos/trechos que devem ser tratados prioritariamente e identificadas as causas dos defeitos reincidentes e de grande impacto nesse sistema, o funcionário responsável pela manutenção do alimentador faz uma inspeção visual e termográfica (inspeção com aparelho termovisor para identificação de pontos quentes), e, através de sua percepção, indica os serviços a serem executados.

Definidos os serviços a serem executados na inspeção nas regiões com o risco inerente, os mesmos foram realizados conforme o critério de prioridade proposto.

O custo total dos serviços executados equivale a $\mathrm{R} \$ 42.344,06$. Dentre esses, tem-se substituição de estruturas, substituição de postes, nivelamento de rede de BT (baixa tensão) e MT (média tensão), execução de 431 podas de árvore e $30 \mathrm{~m}^{2}$ de limpeza de faixa.

A curva do DEC deste alimentador nos anos de 2016 e 2017 é dada na Figura 4.4 . 


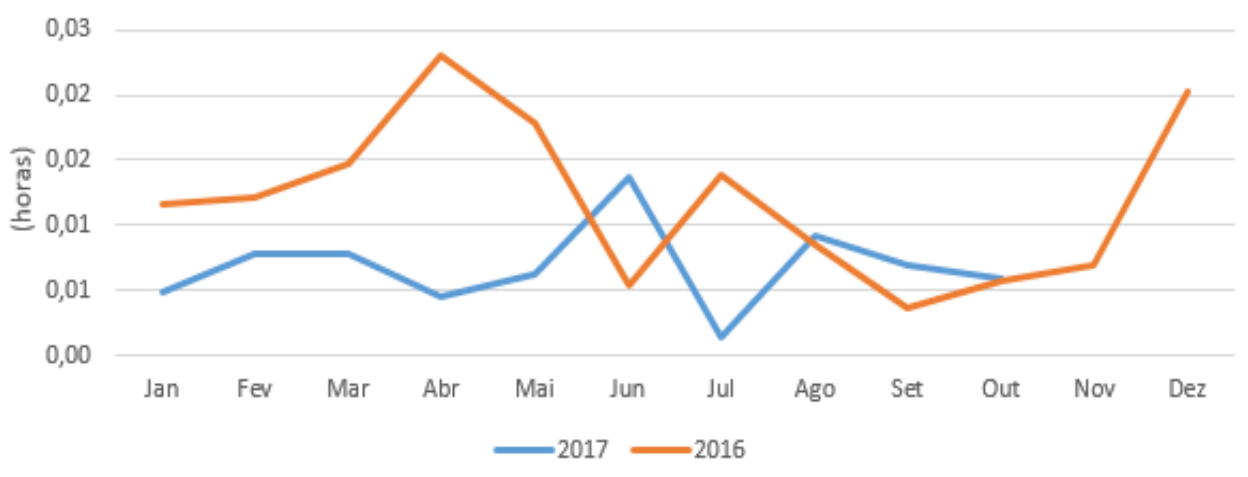

Figura 4.4 - Curva do DEC 2016 versus 2017.

Nota-se uma melhora nos indicadores após a realização das manutenções nos pontos certos. Nota-se ainda que nos meses de junho, agosto e setembro de 2017, o valor de DEC foi maior que o do ano anterior, pois nesses meses, houve o desarme do RD-544805 com atraso de atendimento devido falhas simultâneas em outros alimentadores.

Por sua vez, a compensação financeira para os clientes desse alimentador por parte da concessionária no ano de 2016 equivale a $\mathrm{R} \$ 28.967,06$ e no ano de 2017 equivale a $\mathrm{R} \$ 17.640,03$ (Figura 4.5).

Em suma, a manutenção direcionada para os pontos de maiores impactos nos indicadores de uma rede de distribuição, resulta em uma redução dos indicadores de continuidade e de compensação financeira aos consumidores, o que faz com que aumente a satisfação dos clientes para com a concessionária. 


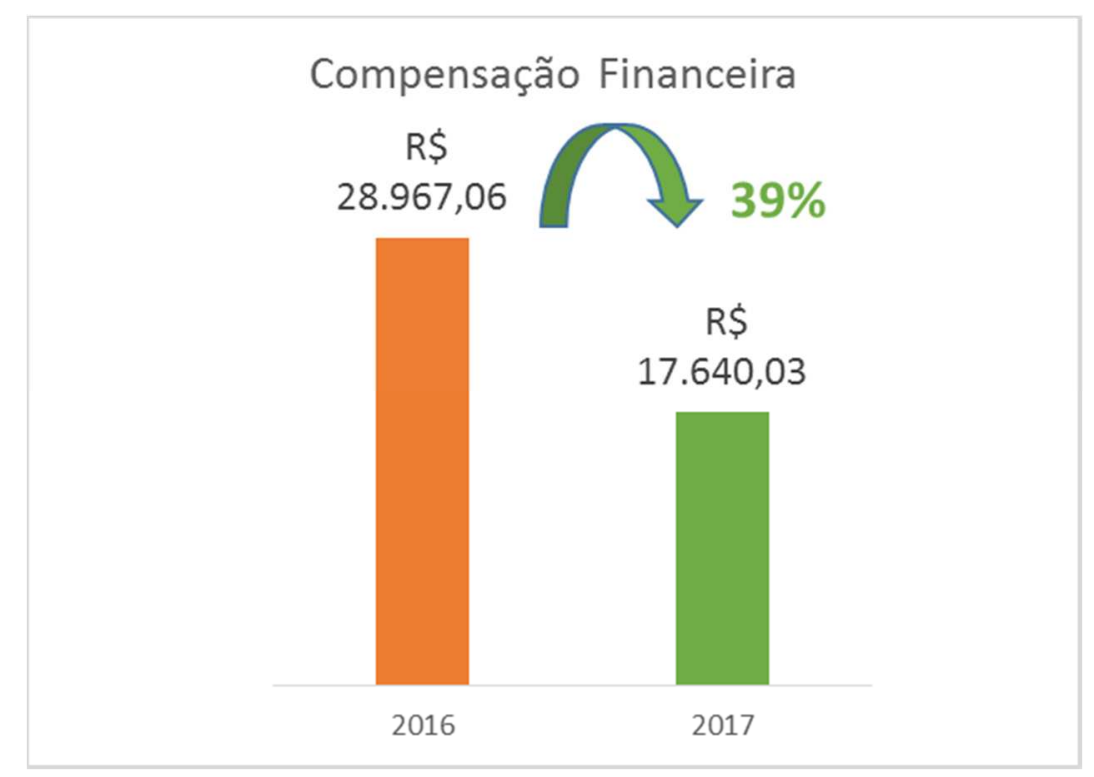

Figura 4.5 - Redução da compensação financeira.

\section{3 Planejamento da Rede}

Para melhorar o desempenho do sistema de distribuição representado através de índices de qualidade, não só a manutenção é suficiente. Em alguns casos, é necessário fazer um planejamento da rede a partir de coordenação e seletividade dos equipamentos de proteção.

A seletividade consiste em isolar somente o ponto atingido pelo defeito a fim de manter a continuidade de energia para as demais cargas conectadas ao sistema, ou ainda, [64] pode ser considerada como a técnica utilizada no estudo de proteção e coordenação, por meio da qual somente o elemento de proteção mais próximo do defeito desconecta a parte defeituosa do restante do sistema.

A alocação de equipamentos de proteção e seccionamento em pontos específicos no sistema de distribuição geram melhorias na qualidade do serviço prestado e restringe ao mínimo a área interrompida.

A metodologia aqui apresentada pode não só auxiliar o direcionamento para manutenções, mas também para planejamento de redes para melhor seletividade de um circuito de distribuição de energia elétrica conforme será apresentado no próximo item. 


\subsection{1}

\section{Sistema-Teste}

O alimentador estudado nesta seção segue a mesma configuração do sistema teste apresentado no item anterior.

Esse sistema teste aqui apresentado é denominado por LDA Coringa. Este circuito é responsável pelo fornecimento de energia de 8807 clientes no município de Barra Mansa. Também é responsável por cargas importantes no município. Sua configuração é radial com recurso em nível de tensão de $13,8 \mathrm{kV}$ sendo originado na mesma SETD descrita anteriormente.

A Figura 4.6 apresenta o caminho do transformador da subestação até o seu disjuntor principal, destacado na cor vermelha.

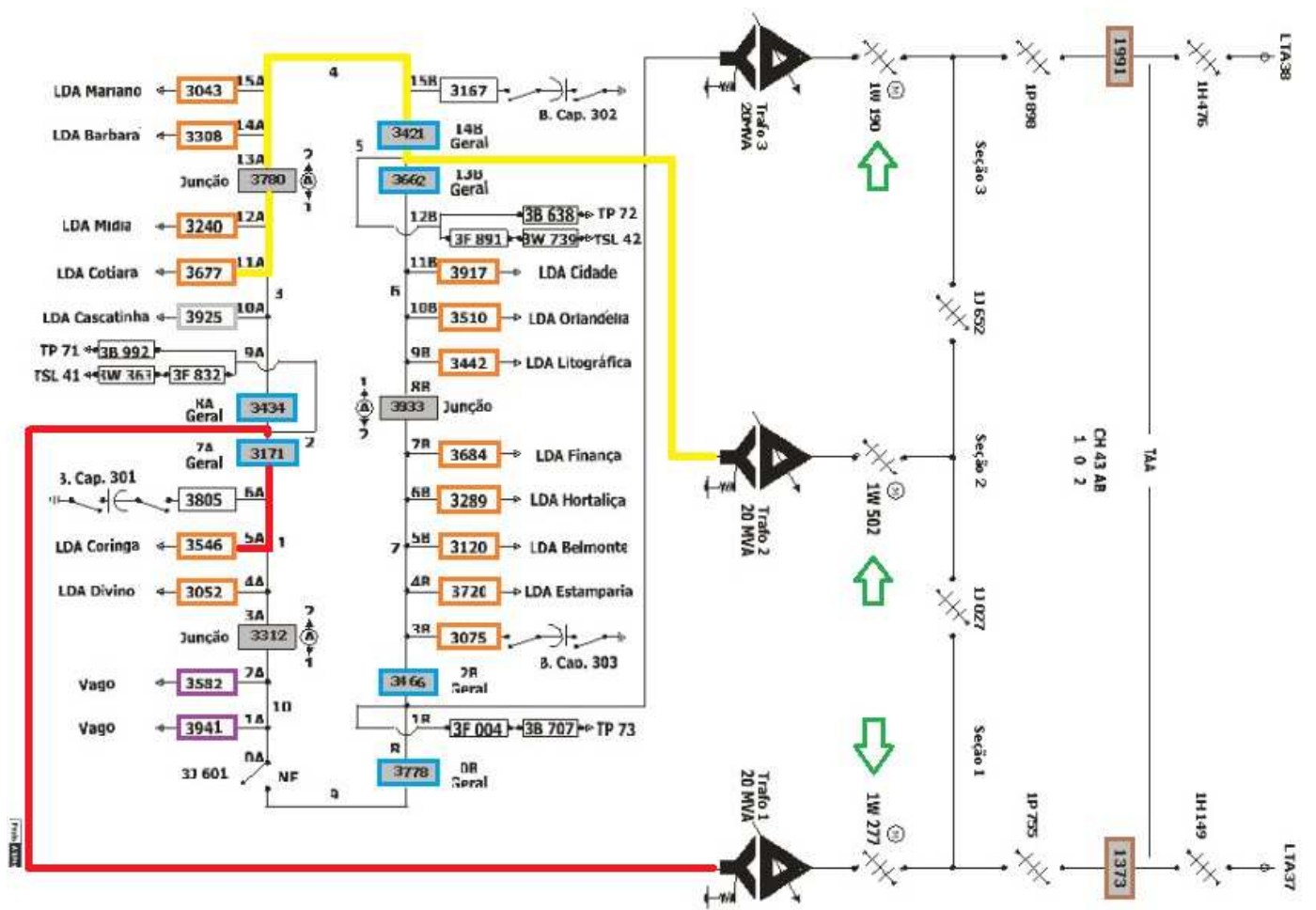

Figura 4.6 - Diagrama SETD: destaque LDA Coringa.

Muitas falhas eram geradas nesse circuito devido à localização de um religador situado próximo ao equipamento de retaguarda. Por sua vez, o religador 
principal (7625 clientes) protegia quase a mesma carga do disjuntor da subestação (8807 clientes).

A Figura 4.7 indica a posição do RD-544803 (destacado em vermelho) em relação ao disjuntor principal (destacado na cor verde). A Figura 4.8 representa uma representação da posição do religador em relação ao disjuntor principal.

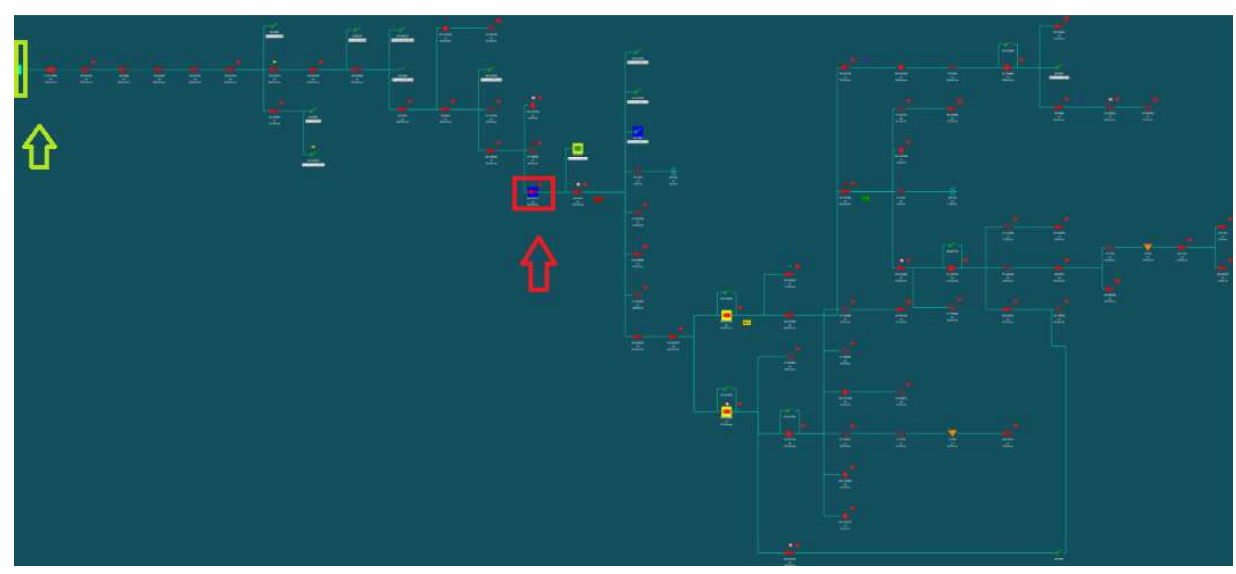

Figura 4.7 - Diagrama de distribuição LDA Coringa [65].

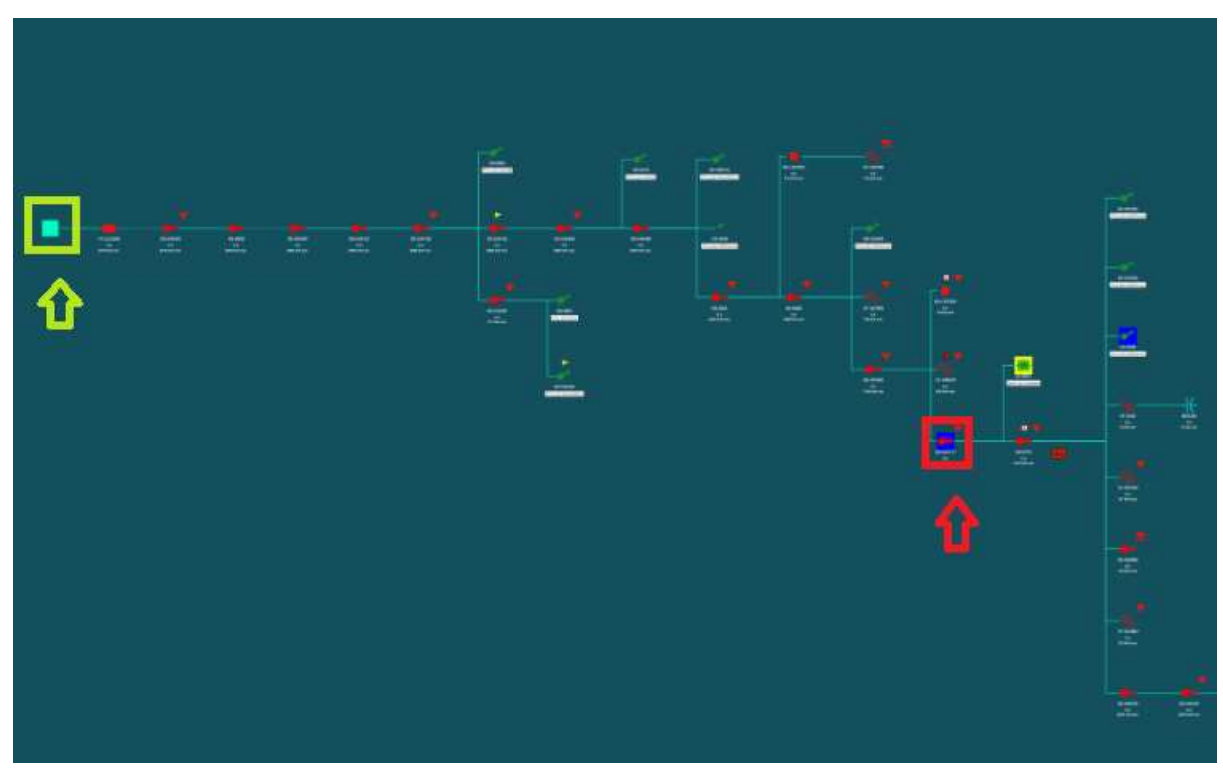

Figura 4.8 - Visão aproximada diagrama de distribuição LDA Coringa [65].

O religador sempre atuou de forma a interromper o fornecimento de energia elétrica às cargas conectadas a jusante dele. Portanto, qualquer defeito apresentado 
(Figura 4.9) na região A (linha amarela) ou região B (linha laranja) poderia ocasionar um defeito e consequentemente o aumento do número de clientes com fornecimento interrompido e, por conseguinte, o aumento do DEC.

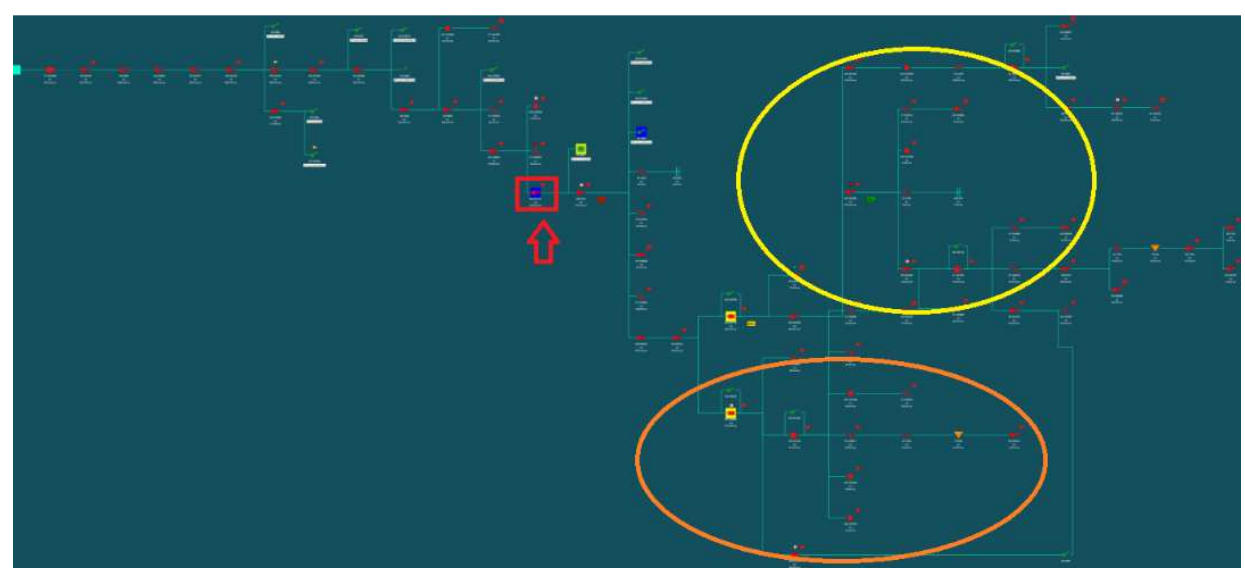

Figura 4.9 - LDA Coringa: Regiões de maiores defeitos [65].

A configuração desta rede de distribuição com todos os componentes pode ser verificada também em Apêndice.

A metodologia de matriz de risco foi aplicada então a esse alimentador para verificar os pontos de maior impacto e reincidência de defeitos nessa rede de distribuição.

\subsection{2}

\section{Resultados}

$\mathrm{Na}$ metodologia proposta, para identificação do risco, tem-se que o alimentador possui 8807 clientes e o tempo médio de restauração é equivalente a 3,39 horas, considerando o histórico do ano de 2016.

Assim, o maior impacto no indicador de continuidade, apontado através do $\mathrm{CHI}_{\text {máx }}$ do circuito-teste, conforme (4.2), é:

$$
\mathrm{CHI}_{\text {máx }}=8.807 \times 3,39=29.855,73 \quad[\text { cliente } \times \mathrm{h}]
$$


Os níveis do eixo de reincidência são dispostos conforme a Tabela 3.1, o eixo do impacto com seus respectivos pesos são de acordo com a Tabela 3.2, a partir do $\mathrm{CHI}_{\text {máx }}$ se encontra na Tabela 4.3.

Tabela 4.3 - Níveis de impacto do sistema teste.

\begin{tabular}{lccc}
\hline \hline Risco & Impacto $\mathbf{C H I}_{\text {máx }}(\boldsymbol{\%})$ & Peso & CHI \\
\hline \hline 5. Crítico & $>13,0$ & 5 & $>3881$ \\
\hline 4. Alto & $>8,0 \mathrm{e} \leq 13,0$ & 4 & 3881 \\
\hline 3. Médio & $>5,0 \mathrm{e} \leq 8,0$ & 3 & 2388 \\
\hline 2. Baixo & $>3,0 \mathrm{e} \leq 5,0$ & 2 & 1492 \\
\hline 1. Mínimo & $3,0 \leq$ & 1 & 895 \\
\hline \hline
\end{tabular}

Para alocação dos equipamentos no mapa de risco, obteve-se o resultado apresentado na Figura 4.10, que indica sete (7) equipamentos/trechos, localizados na região de cor vinho e que apresentam os piores níveis de risco. Ações deverão ser realizadas mais breve possível, uma vez que estes foram alocados devido ao maior impacto nos indicadores.

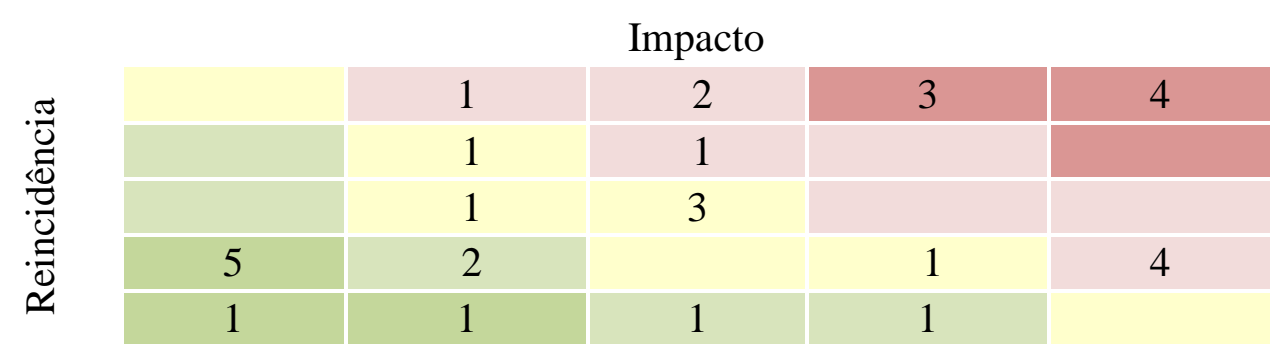

Figura 4.10 - Matriz de Risco do circuito teste.

Para o tratamento dos riscos, como havia muitos defeitos por falta de seletividade, as soluções identificadas pelo técnico de manutenção e engenheiro responsável pela área, foram: realocação de alguns equipamentos de proteção e instalação de novos equipamentos de proteção. Nesse caso, como a solução para minimizar a quantidade de clientes interrompidos, não foi considerada a compensação financeira. 
Tabela 4.4 - Trechos e/ou equipamentos com risco inerente.

\begin{tabular}{lcc}
\hline \hline Equipamento/Trecho & Nível Reincidência & Nível Impacto \\
\hline \hline ZNA120176 & Eminente & Alto \\
\hline CF-534040 & Eminente & Alto \\
\hline CF-7794 & Eminente & Alto \\
\hline RD-544803 & Eminente & Crítico \\
\hline SL-6027 & Eminente & Crítico \\
\hline ZNA110233 & Eminente & Crítico \\
\hline ZNA111045 & Eminente & Crítico \\
\hline \hline
\end{tabular}

Foi levado em consideração o trecho reincidente e a carga protegida, além do conhecimento prévio da topologia do circuito já que a rede percorre morros e locais de difícil acesso. Igualmente, foram consideradas também as cargas mais importantes para este circuito.

As mudanças realizadas nesse alimentador foram:

- $\quad$ Realocação do religador RD-544803 do Ponto A (ponto da KS-547177) para o Ponto B (Figura 4.11);

- Instalação do religador RD-547102 no Ponto C (Figura 4.11), protegendo o alimentador dos defeitos reincidentes na região A (indicada na cor amarela Figura na 4.9); 


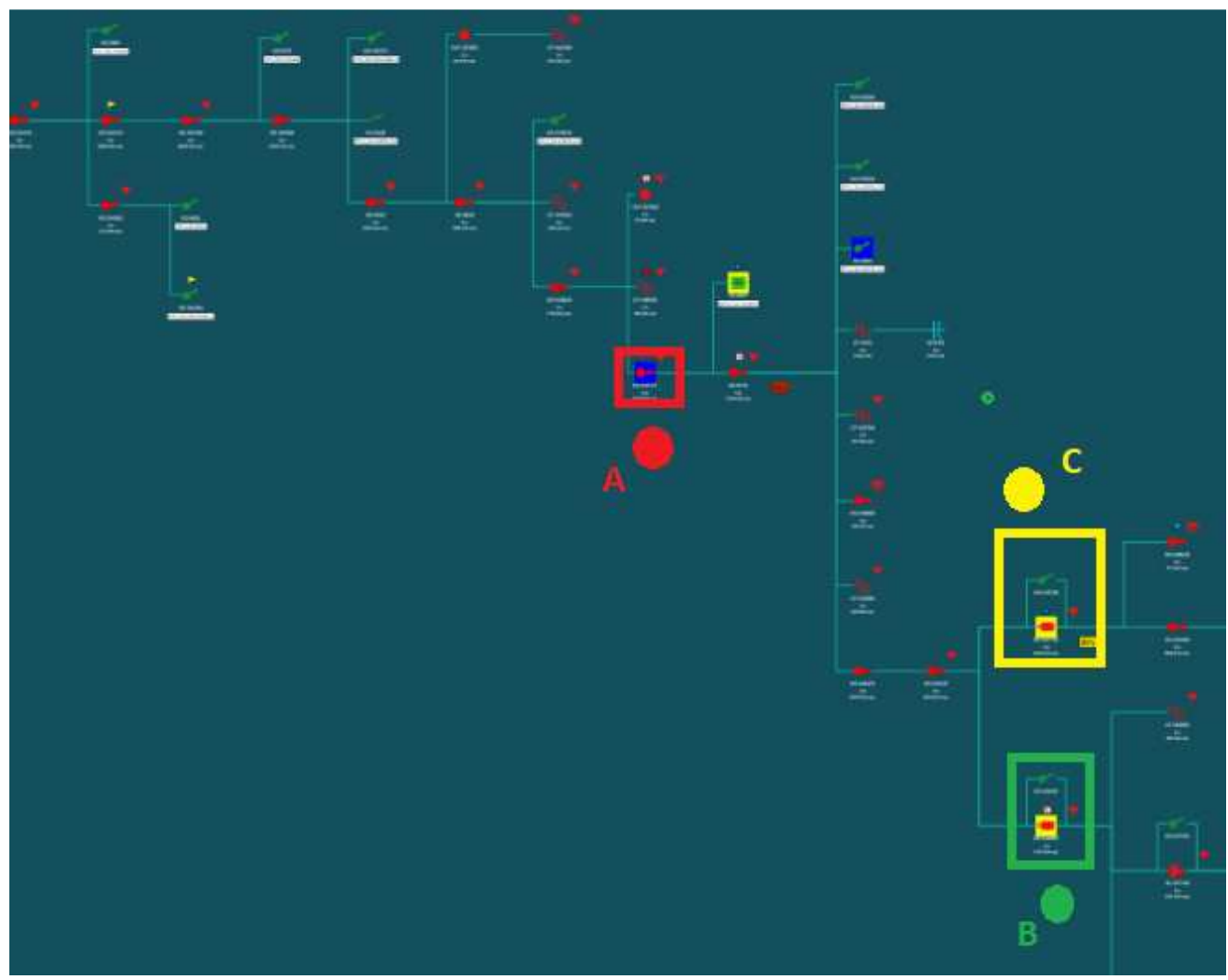

Figura 4.11 - Alteração 1: LDA Coringa [65].

- Instalação do seccionalizador SL-547149 no ponto D (Figura 4.12), protegendo o alimentador dos defeitos reincidentes na região B (indicada na cor laranja na Figura 4.9);

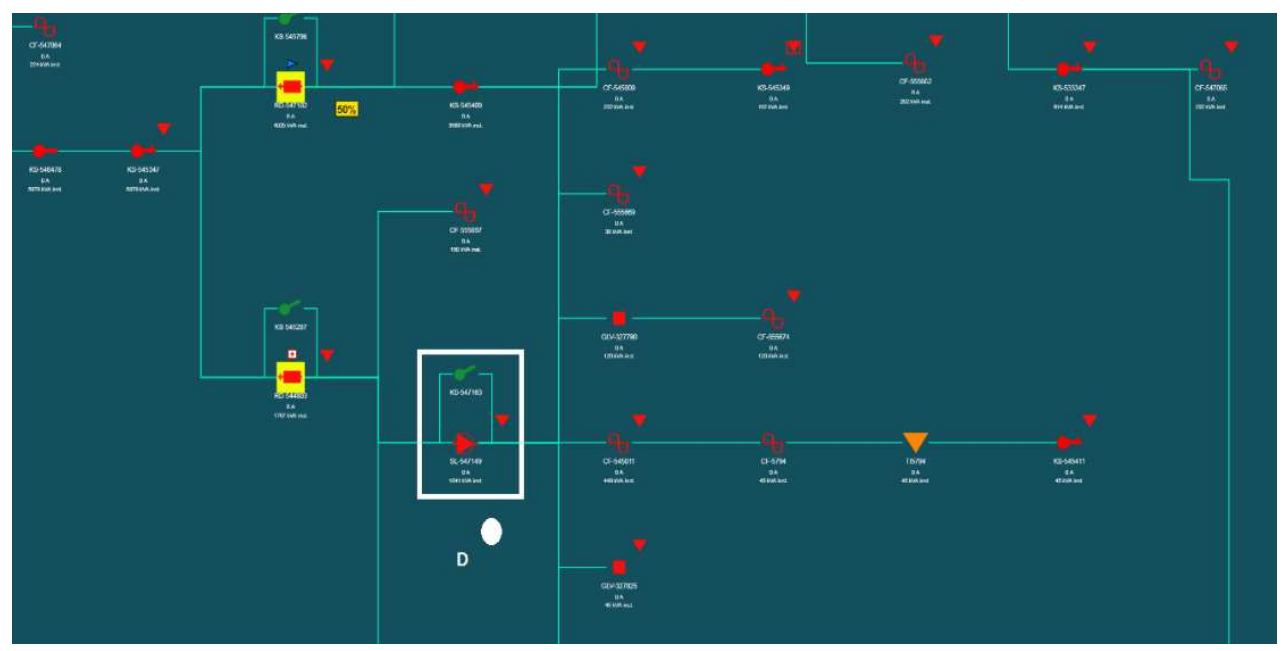

Figura 4.12 - Alteração 2: LDA Coringa [65]. 
- Instalação do seccionalizador SL-544993 (Figura 4.13), protegendo o alimentador dos defeitos reincidentes na região A (indicada na cor amarela na Figura 4.9);

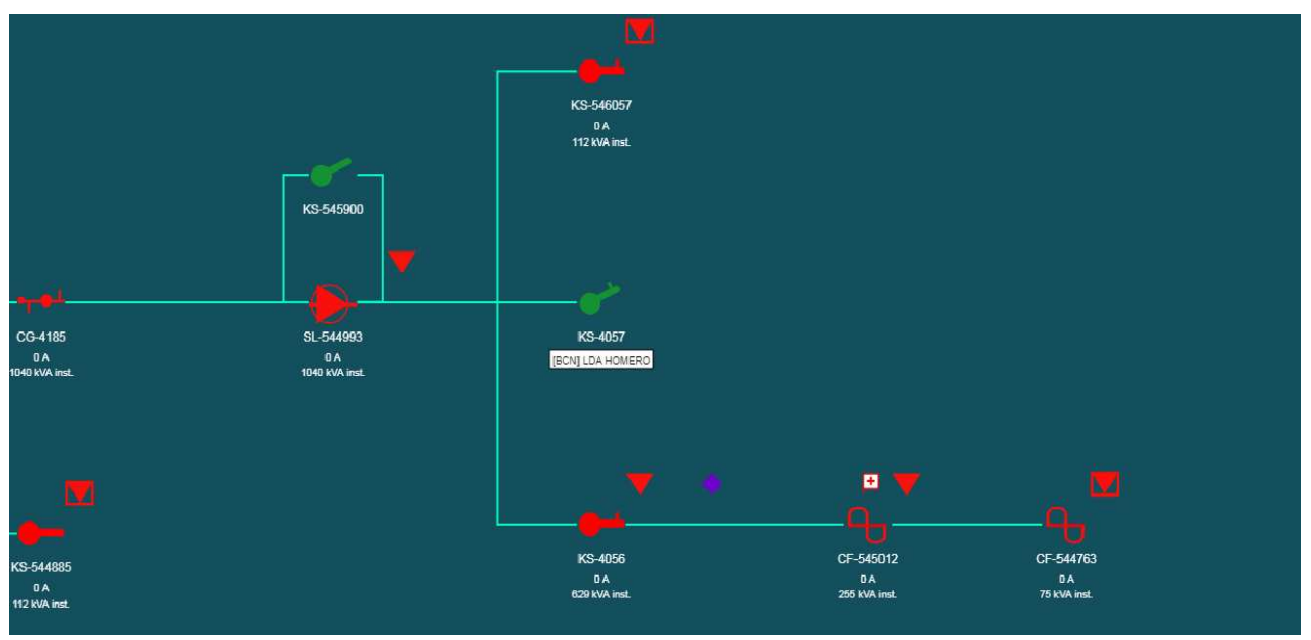

Figura 4.13 - Alteração 3: LDA Coringa [65].

- Realocação do SL-547164, para proteger os consumidores da região B (indicada na cor laranja na Figura 4.14).

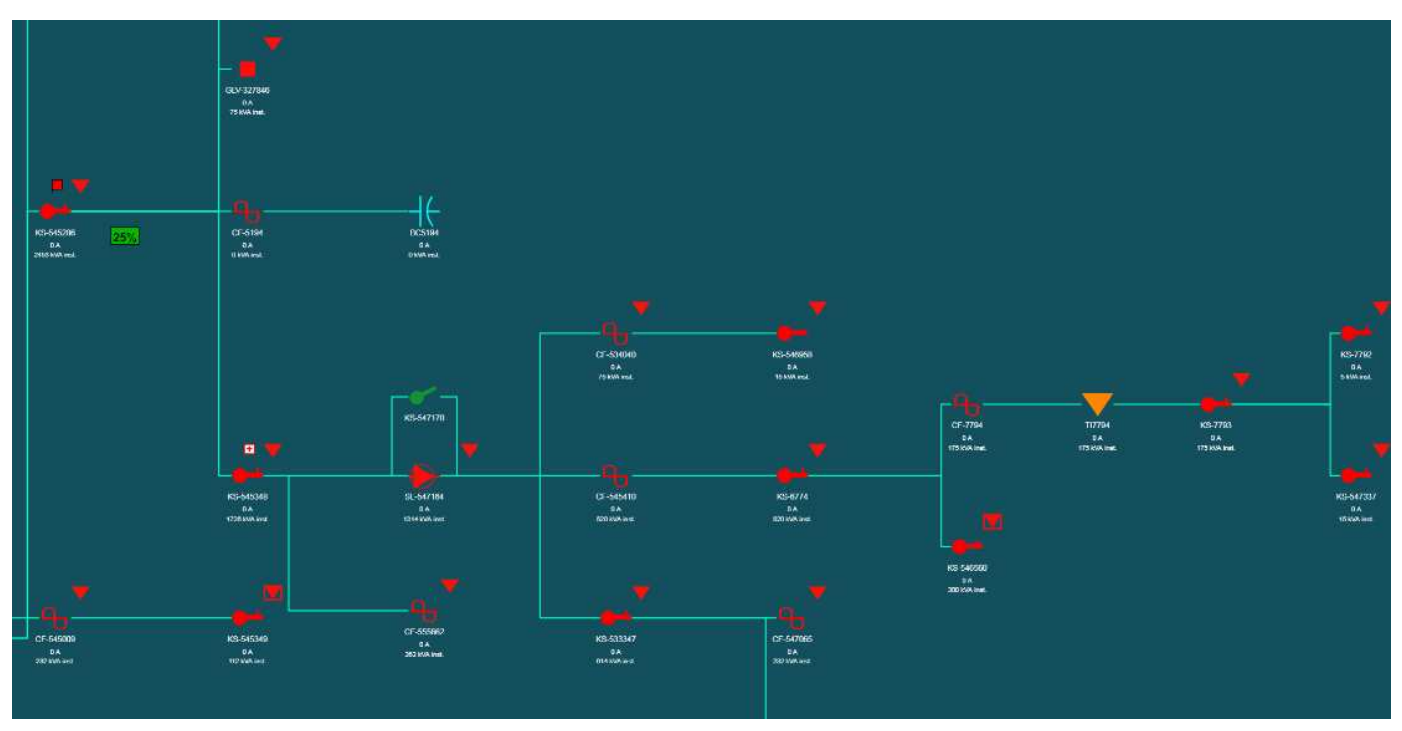

Figura 4.14 - Alteração 4: LDA Coringa [65]. 
Para a nova configuração, a linha apresenta maior seletividade, já que para defeitos reincidentes na região A, o equipamento a desarmar é o RD-547102, e os clientes na região B não sentem essa falta. E, da mesma forma, para a região $\mathrm{B}$, foi realocado o RD-544803, e instalado o SL-547149, restringindo a área que ficará sem energia quando houver falhas nessa região, protegendo, portanto os clientes da região A.

O custo total dos serviços executados equivale a $\mathrm{R} \$ 69.568,25$. Os mesmos foram realizados no mês de Julho e Agosto de 2017.

A curva do DEC deste alimentador nos anos de 2016 e 2017 é dada na Figura 4.12 .

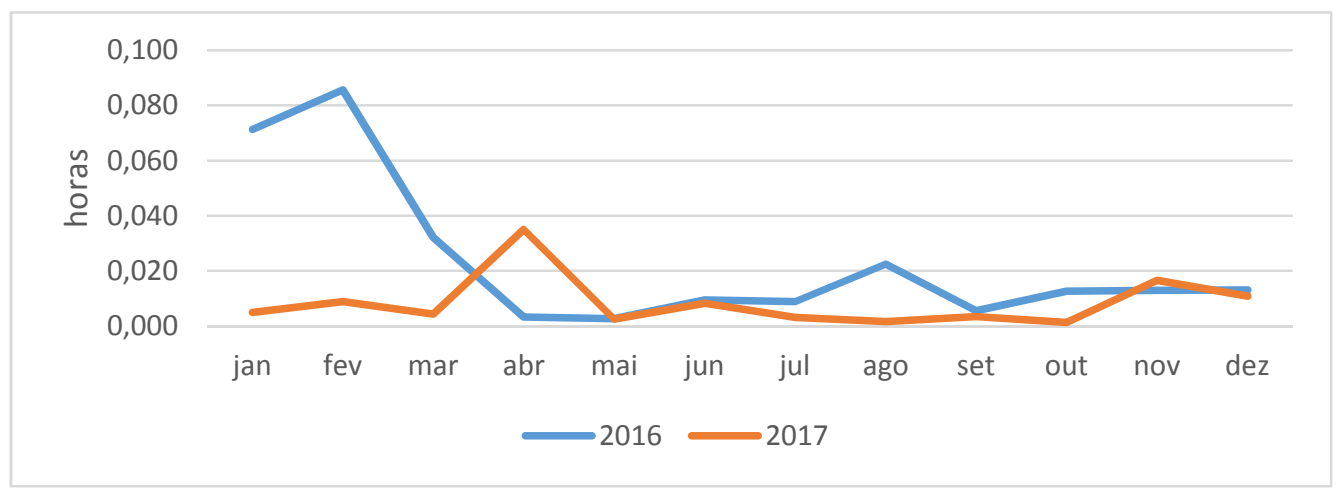

Figura 4.15 - Curva do DEC 2016 versus 2017.

Nota-se uma melhora significativa nos indicadores após a realização de seletividade nos pontos certos. Nota-se ainda que nos meses de abril e novembro de 2017, o valor do indicador DEC foi maior que o do ano anterior, entretanto, quando considerado o valor acumulado, é possível concluir que houve a redução de $64 \%$ (Figura 4.16). 


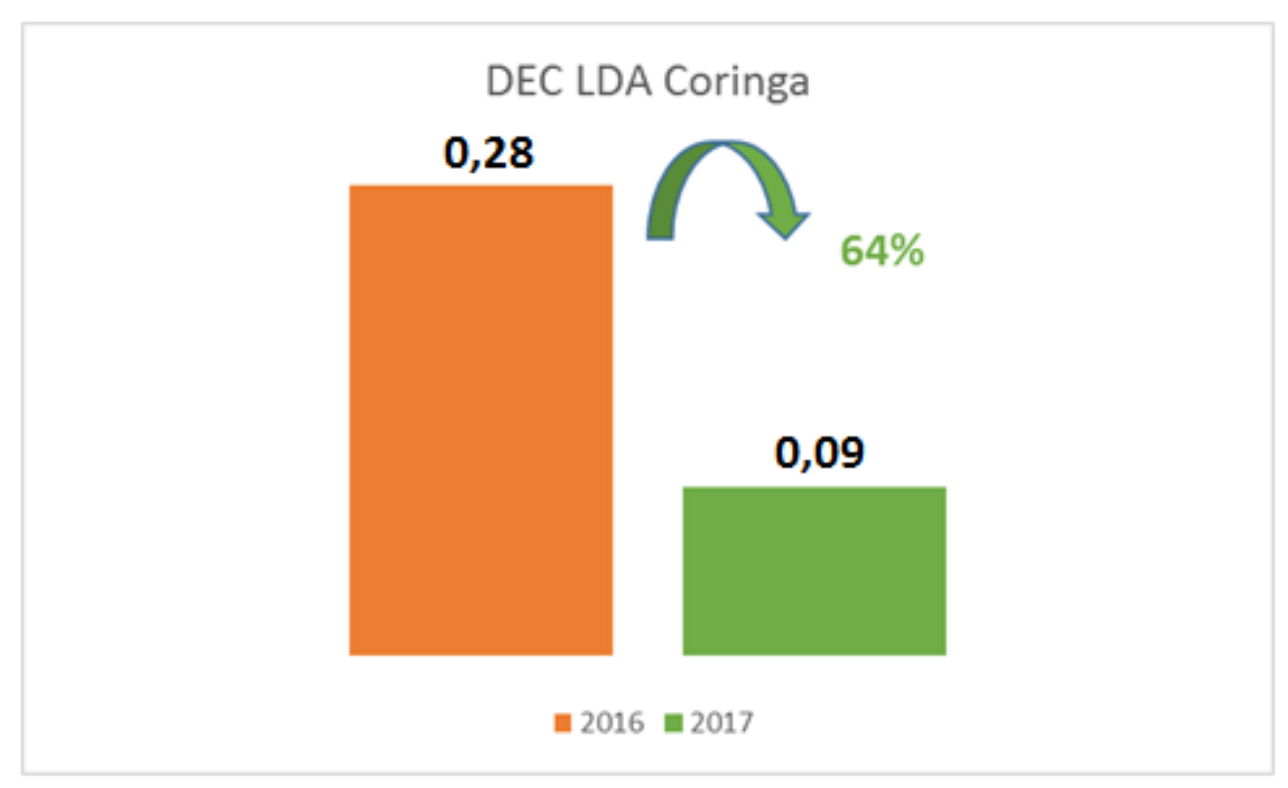

Figura 4.16 - DEC LDA Coringa.

Por sua vez, a compensação financeira para os clientes desse alimentador por parte da concessionária no ano de 2016 equivale a $\mathrm{R} \$ 20.860,00$ e no ano de 2017 equivale a $\mathrm{R} \$ 34.385,00$ (Figura 4.17).

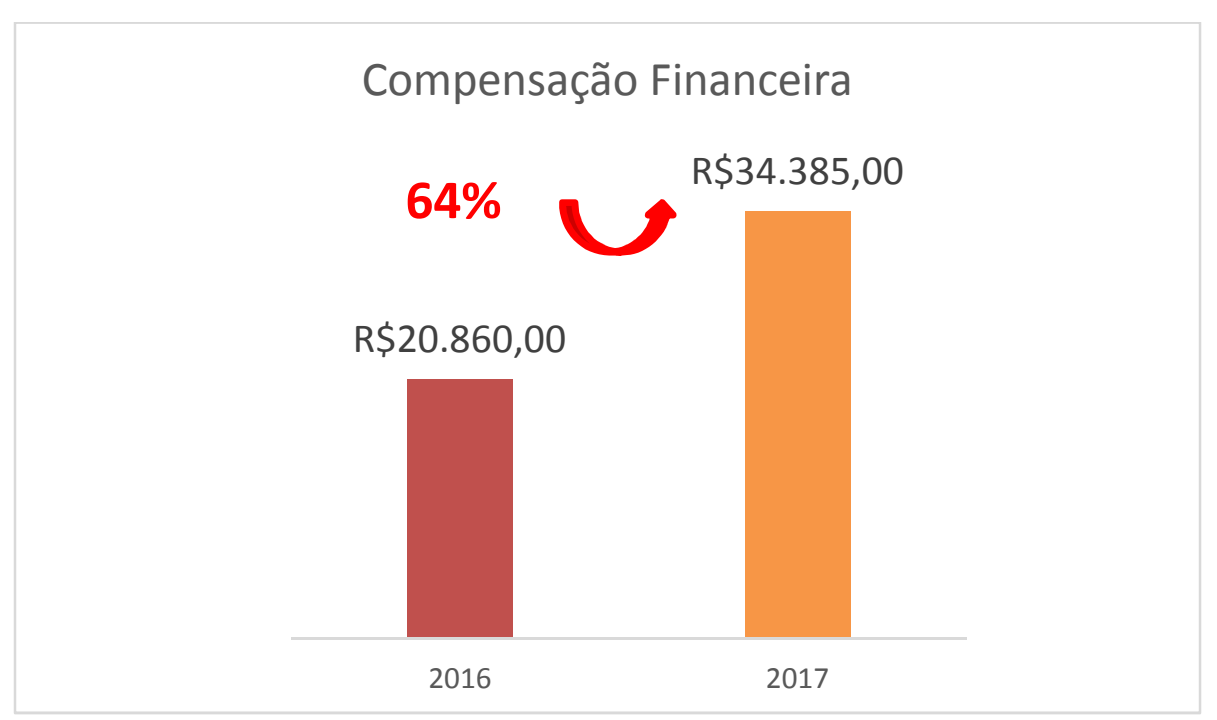

Figura 4.17 - Compensação Financeira LDA Coringa.

No mês de Fevereiro/2017 ocorreram três desarmes consecutivos do RD544803 por falhas de equipe e processo. Nesse mês, a compensação financeira foi de R\$ 15.629,00. O custo aumentou devido ocorrências em um mês "atípico". 
Em suma, a manutenção pode ser direcionada não só para manutenções corretivas, como também, para melhorias no sistema elétrico quanto à proteção e seletividade. Isso resulta em uma redução dos indicadores de continuidade e aumente a satisfação dos clientes para com a concessionária, uma vez que os mesmos terão menor número e menor duração de interrupções no fornecimento de energia elétrica.

\section{4 \\ Conclusão}

Os resultados apresentados confirmam que a metodologia proposta através da matriz de risco é satisfatória no sentido de identificar os pontos que demandam maior intervenção preventiva.

A identificação dos pontos considerados críticos por sua vez favorece uma diminuição nos prejuízos à concessionária de energia elétrica uma vez que mantém a oferta (desonerando o prejuízo dos clientes) e assim atendendo às metas do órgão regulador.

Um procedimento simples pode ser realizado em uma planilha do Excel onde através da quantificação do tempo médio das interrupções e considerando o histórico de ocorrência de falhas é possível estimar a probabilidade de ocorrência de determinados níveis críticos e localizá-los na rede de sistema de distribuição de energia.

Em vistas de um orçamento limitado no tocante à manutenção, essas técnicas contribuem positivamente na mitigação das interrupções de energia e mantém a qualidade e a oferta da energia elétrica ao consumidor final. 


\section{5 \\ Conclusões}

Um sistema de distribuição está vulnerável a falhas em seus equipamentos. Esses problemas não previstos, somados à necessidade das concessionárias de garantir boa qualidade no fornecimento de energia, geram novos estudos e análises para obtenção do ponto ótimo de confiabilidade, com o menor custo possível e bons indicadores de desempenho. Devem ser levadas em consideração as limitações de orçamento das empresas concessionárias de energia, para que seja possível garantir a satisfação do cliente, não pagar penalidades e atingir as metas estabelecidas. Portanto, a atuação das empresas distribuidoras de energia elétrica precisa ser efetiva no planejamento da manutenção de seus equipamentos.

A presente dissertação apresentou uma metodologia capaz de identificar os equipamentos e circuitos associados aos pontos críticos e de maior impacto em uma rede de distribuição. Desta forma, foi possível direcionar os serviços de manutenção para os trechos de maior impacto nos índices de continuidade de uma determinada região e otimizar o orçamento correspondente. A ferramenta usada para analisar os indicadores é uma Matriz de Risco, onde os eixos representam probabilidade de ocorrência (reincidência) e impacto corporativo (índice de continuidade), de modo a capturar com maior precisão os pontos de manutenção prioritária. Os fatores de risco identificados são avaliados qualitativamente, em termos de probabilidade e impacto, e posicionado na matriz, indicando seu estado como eminente, crítico, alto, médio e baixo.

Foram analisados dois sistemas de distribuição reais, com o objetivo de demonstrar a capacidade da metodologia proposta de encontrar as soluções condizentes do ponto de vista técnico e econômico. Os resultados apontam uma redução dos indicadores de continuidade, colaborando assim na eficaz gestão do sistema elétrico e na minimização dos prejuízos econômicos associados às interrupções de energia. 
Através da metodologia proposta nesta dissertação, foi possível um direcionamento mais assertivo tanto para o planejamento quanto para a execução das manutenções nas redes que poderão evitar futuros defeitos. Analisando os resultados encontrados, o gasto que teve com a manutenção realizada foi maior que o valor da compensação financeira paga no ano considerado, entretanto, houve a redução do indicador de continuidade DEC. Nota-se também, uma redução no valor de compensação financeira paga aos clientes do circuito-teste [66].

Vale ressaltar que a matriz também pode ser utilizada como uma indicação dos pontos críticos não só na execução de serviços mas também na inspeção, momento em que são levantados em campo os serviços a serem realizados. Isto porque o técnico pode aproveitar desta informação para ir a campo com foco nos equipamentos críticos. Do ponto de vista operacional, a adoção de medidas como essa, combinada com a matriz de risco, apresenta para a concessionária os pontos críticos a serem observados e isso facilita na programação dos investimentos destinados à manutenção da rede.

Por sua vez, a manutenção eficaz garante $o$ atendimento às metas estabelecidas pelo órgão regulador e desoneram das penalidades as concessionárias, por atenderem à oferta de energia ao consumidor e acabam por inferir positivamente na qualidade do serviço prestado.

O período observado para comparação do histórico dos indicadores foi de 2 (dois) anos. Como as redes de distribuição estão expostas às diversas variáveis, podem ocorrer defeitos em trechos que não foram identificados pela matriz e que impactem no indicador no período seguinte.

Como recomendações futuras podem auxiliar no planejamento e na gestão das falhas algumas medidas:

- Criação de um banco de dados com o histórico de ocorrência de falhas;

- Aplicação de uma nova metodologia para melhorar o indicador de compensação financeira;

- Consideração da variável meteorológica (condições adversas do sistema atmosférico) na Matriz de Risco; 
- Execução de um plano de ação a curto, médio e longo prazos considerando o histórico de ocorrência de falhas e identificando os pontos considerados críticos;

- Capacitação dos técnicos com relação à operabilidade dessa ferramenta.

Os resultados revelam que os indicadores que impactam sobre a possibilidade do cumprimento de metas estabelecidas pelo órgão regulador são o caminho para se discutir a eficácia na resposta às constantes interrupções de energia. $\mathrm{O}$ histórico de falhas identificado gera um tempo médio e assim, os níveis de alerta podem ser facilmente localizados na rede de distribuição antes mesmo que possam ocorrer na prática.

À concessionária de energia elétrica que é quem presta o serviço fica a responsabilidade de direcionar melhor os investimentos para a manutenção e mitigar, assim, a ocorrência de interrupções de energia ao consumidor. Deste modo, as metas estabelecidas podem ser alcançadas sem que ocorra uma penalidade por parte de falhas nos equipamentos.

Ao consumidor final, o cliente, a oferta de energia pode estar assegurada uma vez que as falhas identificadas revelam os equipamentos que devam ser substituídos e assim, não comprometam o fornecimento de energia. Por parte do cliente, a compensação financeira pode ser no sentido de não haver um custo gerado em função dessa manutenção emergencial visto que a preventiva já atuou em outro momento. 


\section{Referências Bibliográficas}

[1] ROSA, L. P.; SENRA, P. M. A., Participação Privada na Expansão do Setor Elétrico ou Venda das Empresas Públicas? COPPE/UFRJ, Rio de Janeiro, 1995.

[2] LEITE, A. D., A Energia do Brasil. Nova Fronteira, Rio de janeiro, 1997 $2^{\mathrm{a}}$ impressão.

[3] KAGAN, N.; OLIVEIRA C. C. B.; ROBBA, E. J., Introdução aos Sistemas de Distribuição de Energia Elétrica. 2ª Edição, São Paulo, Brasil, Blucher, 2005.

[4] BILlintON R.; ALLAN R. N., Reliability Evaluation of Power Systems. 2nd Edition, New York, Plenum Press, 1996.

[5] LI W., Risk Assessment of Power Systems - Models, Methods, and Applications. New York: IEEE Press, 2005.

[6] BILlinTON R.; LI, W., Reliability Assessment of Electric Power Systems Using Monte Carlo Methods. New York, Plenum, 1994.

[7] BILLINTON R.; ALLAN R.N., Reliability Evaluation of Engineering Systems - Concepts and Techniques. 2nd. Edition, New York, Plenum Press, 1992.

[8] FONG, C. C.; BILLINTON R.; et al., Bulk System Reliability - Measurement and Indices. IEEE Trans. on Power Systems, vol. 4, no 3, pp. 829-835, Aug. 1989.

[9] OPERADOR NACIONAL DO SISTEMA ELÉTRICO - ONS, Procedimentos de Rede - Submódulo 23.3. ONS, www.ons.org.br.

[10] NUNES, J. S., Impacto da Confiabilidade de Redes de Transmissão e Subtransmissão nos Índices de Desempenho de Sistemas de Distribuição. Dissertação de Mestrado. UNIFEI, Itajubá, MG, Dez. 2017.

[11] DEPATARMENTO NACIONAL DE ÁGUAS E ENERGIA ELÉTRICA DNAEE, PORTARIA No 46, DE 17 DE ABRIL DE 1978. Brasília (DF), 1978. Acesso em Agosto de 2018. 
[12] SCHILling M. T.; SOUZA, J. C. S.; DO COUTTO FILHO, M. B., Power System Probabilistic Reliability Assessment: Current Procedures in Brazil. IEEE Trans. on Power Systems, vol. 23, nº 3, Aug. 2008.

[13] LEITE DA SILVA, A. M.; CASSUlA, A. M.; BILlinTON, R.; MANSO, L. A. F., Integrated Reliability Evaluation of Generation, Transmission and Distribution Systems. Proc. IEE-GTD, vol. 149, nº 1, pp. 1-6, Jan. 2002.

[14] PEREIRA, M. V. F.; BALU, N. J., Composite Generation/Transmission Reliability Evaluation, Proc. of the IEEE, vol. 80, nº 4, April 1982.

[15] MELO, A. C. G.; PEREIRA, M. V. F.; LEITE DA SILVA, A. M., Frequency and Duration Calculations in Composite Generation and Transmission Reliability Evaluation. IEEE Trans. on Power Systems, vol. 7, nº 2, pp. 469476, May 1992.

[16] MANSO, L. A. F., Um ambiente para sistemas de Geração e Transmissão utilizando o Valor da Confiabilidade. Tese Doutorado, Universidade Federal de Itajubá, UNIFEI, MG, 1999.

[17] GAVER, D. P.; MONTMEAT, F. E.; PATtOn, A. D., Power System Reliability: I - Measures and Methods of Calculation. IEEE Trans. on Power Apparatus Systems, vol. 83, nº 7, pp. 727-737, Jul. 1964.

[18] TODD, Z. G., A Probability Method for Transmission and Distribution Outage Calculations. IEEE Trans. on Power Apparatus and Systems, vol. 83, nº 7, pp. 696-701, Jul. 1964.

[19] GUIMARAES, A. C. R., Confiabilidade de Sistemas de Distribuição: Calibração de Dados e Mecanismos para Avaliação de Desempenho. Dissertação de Mestrado, Universidade Federal de Itajubá, UNIFEI, MG, 2006.

[20] MALlARD, A.; THOMAS, V. C., A Method for Calculating Transmission System Reliability. IEEE Trans. on Power Apparatus and Systems, vol. PAS-87, nº 3, pp. 824-834, Mar. 1968.

[21] BILlintON, R.; BOLlingER, K. E., Transmission System Reliability Evaluation Using Markov Processes. IEEE Trans. on Power Apparatus and Systems, vol. PAS-87, $\mathrm{n}^{\circ}$ 2, pp. 538-547, Feb. 1968.

[22] PATTON, A. D., Probability Distributions of Transmission and Distribution Reliability Performance Indices. Reliability Conference for Electric Power Industry, pp. 120-122, 1979. 
[23] BILlinton R.; ALlAN R. N.; BREIPOHL, A. M.; GRIGG, C. H., Bibliography on the Application of Probability Methods in Power System Reliability Evaluation 1992-1996. IEEE Trans. on. Power Systems, vol. 14, no 1, pp. 51-57, Feb. 1999.

[24] BILLINTON, R.; LIAN, G., Station Reliability Evaluation Using a Monte Carlo Approach. IEEE Trans. on Power Delivery, vol. 8, no 3, pp. 12391245, Jul 1993

[25] BERTLING, L.; ANDERSSON, G.; ALLAN, R. N., Reliability Centered Maintenance Applied to Electrical Distribution Systems. International Conference on Electric Power Engineering PowerTech Budapest 99, pp. 261261, 1999.

[26] DONIAK J. A.; MASSUDA M.; PEREIRA E. G.; KLIMKOWSKI M.; SCIAMMARELLA S. F.; BASSLER, M.; SUCKOW C. J.; VIVEKANANDA R., Desenvolvimento de Metodologia de Manutenção Baseada em Confiabilidade para Redes de Distribuição Urbanas da ENERSUL. II CITENEL, Programa de P \& D da ENERSUL. LACTEC. 2003.

[27] SIQUEIRA, I. P., Manutenção Centrada em Confiabilidade: Manual de Implementação. Editora Qualitymark, Rio de Janeiro, 2005.

[28] DIAS, E. J. Inspeção Filmada em Redes de Distribuição Aéreas de Energia Elétrica. SENDI - Seminário Nacional de Distribuição de Energia Elétrica, 2004.

[29] LORETO, A. C. D.; MENDONÇA, J. W. L; JUNIOR, L. S., Nova Metodologia de Critérios e Diretrizes de Inspeção e Manutenção no Sistema de Distribuição de Energia Elétrica. X INIC/VI EPG - UNIVAP, 2006.

[30] CHOWdhury, A. A.; KOVAL, D. O., Power Distribution System Reliability: Practical Methods and Applications. Wiley-IEEE Press, New Jersey, 2009.

[31] Singh, C.; JiRUtiJiJAROEN, P.; MITRA, J., Electric Power Grid Reliability Evaluation: Models and Methods. Wiley-IEEE Press, N.J., 2009.

[32] BROWN, R. E., Electric Power Distribution Reliability. $2^{\text {nd }}$ Edition, Marcel Dekker Inc., New York, 2002. 
[33] CASSULA, A. M., Avaliação Integrada da Confiabilidade de Sistemas de Geração, Transmissão e Distribuição Baseada em Simulação Cronológica. Tese de Doutorado, Universidade Federal de Itajubá, UNIFEI, Itajubá, MG, Junho 2002.

[34] SACRAMENTO, C. E., Avaliação da Confiabilidade no Planejamento de Sistemas de Distribuição. Dissertação de Mestrado, Universidade Federal de Itajubá, UNIFEI, Itajubá, MG, Junho 2002.

[35] SCHMITT, W. F., Confiabilidade de Sistemas de Distribuição: Metodologias Analítica e Cronológica. Dissertação de Mestrado, Universidade Federal de Itajubá, UNIFEI, Itajubá, MG, Outubro 2002.

[36] NASCIMENTO, L. C., Avaliação da Confiabilidade de Sistemas de Distribuição Utilizando Processamento Distribuído. Tese de Doutorado, Universidade Federal de Itajubá, UNIFEI, Itajubá, MG, Agosto 2009.

[37] NUNES, J. S., Impacto da Confiabilidade de Redes de Transmissão e Subtransmissão nos Índices de Desempenho de Sistemas de Distribuição. Dissertação de Mestrado, Universidade Federal de Itajubá, UNIFEI, Itajubá, MG, Dezembro 2017.

[38] CASSUla, A. M.; LEITE DA SILVA, A. M.; BILlinTON, R.; MANSO, L. A. F.; SACRAMENTO, C. E. Sacramento, Avaliação Integrada da Confiabilidade de Sistemas de Geração, Transmissão e Distribuição. Anais do VII SEPOPE - Simpósio de Especialistas em Planejamento da Operação e Expansão Elétrica, Curitiba, Paraná, artigo SP-029, CD-ROM, Maio 2000.

[39] LEITE DA SIlVA, A. M.; CASSUlA, A. M.; SACRAMENTO, C. E., Reliability Evaluation of Distribution Systems Under Load Transfer Restrictions. Proceedings of the 7th PMAPS - Probability Methods Applied to Power Systems, Naples, Itália, vol. I, pp. 9 - 14, Sept./2002.

[40] CASSUlA, A. M.; LEITE DA SILVA, A. M.; SACRAMENTO, C. E.; L. A. F., MANSO, Avaliação Integrada da Confiabilidade de Sistemas de Geração, Transmissão e Distribuição Baseada em Simulação Cronológica. Anais do XVII SNPTEE - Seminário Nacional de Produção e Transmissão de Energia Elétrica, Uberlândia, MG, artigo GAT-039, CDROM, 19 - 24 de Outubro, 2003.

[41] CASSUlA, A. M.; LEITE DA SILVA, A. M.; SACRAMENTO, C. E., Uma Nova Proposta para a Incidência de Multas Devido ao Não- 
Cumprimento das Metas de Continuidade em Sistemas de Distribuição. Anais do IX SEPOPE - Simpósio de Especialistas em Planejamento da Operação e Expansão Elétrica, Rio de Janeiro, RJ, 23 -27 Maio, 2004.

[42] LEITE DA SILVA, A. M.; CASSUlA, A. M.; RESENDE, L. C.; ALMEIDA, R. M.; YAMASAKI, M. T.; PAULA, G. M. F., Reliability Evaluation of Distribution Systems Considering Automatic Reclosers. Proceedings of the 8th PMAPS - Probability Methods Applied to Power Systems, Ames, USA, CD-ROM, 12-16/Sept./2004.

[43] LEITE DA SILVA, A. M.; SCHMITT W. F.; CASSUlA, A. M.; SACRAMENTO, C. E., Analytical and Monte Carlo Approaches to Evaluate Probability Distributions of Interruption Duration. IEEE Trans. on Power Systems, vol. 20, nº 3, pp. 1341-1348, August 2005.

[44] LeITE DA Silva, A. M.; CASSUlA, A. M.; NASCIMENO, L. C.; FREIRE JR., J. C.; SACRAMENTO, C. E.; GUIMARÃES, A. C. R., Chronological Monte Carlo-Based Assessment of Distribution System Reliability. Procs. of the 9th PMAPS - Probabilistic Methods Applied to Power Systems, Stockholm, Sweden, CD-ROM, 11-15/June/2006.

[45] GUIMARÃES, A. C. R., NASCIMENO, L. C.; LEITE DA SILVA, A. M.; CASsulA, A. M.; SACRAMENTO, C. E., Avaliação das Metas de Continuidade de Sistemas de Distribuição por Mecanismos Baseados em Desempenho. Anais do XVI CBA - Congresso Brasileiro de Automática, Salvador, BA, 3 - 6 de Outubro, 2006.

[46] LeITE DA Silva, A. M.; NASCIMENO, L. C.; CASSUlA, A. M.; SACRAMENTO, C. E., ÁVILA, A. F., Network Reconfiguration of Distribution Systems Using Metaheuristic Techniques and Reliability. Proceedings of the 15th ISAP - International Conference on Intelligent System Applications to Power Systems, paper 147, CD-ROM, Curitiba, Brazil, 8-12/November, 2009.

[47] LEITE DA SILVA, A. M.; NASCIMENTO, L. C.; GUIMARÃES, A. C. R.; MELLO, J. C. O., Reliability Indices Applied to Performance-Based Mechanisms in Electric Power Distribution Systems. International Journal of Systems Assurance Engineering and Management, Springer, vol. 1, n ${ }^{\circ}$ 2, pp. 105-112, 2010. 
[48] NUNES, J. S.; LEITE DA SILVA, A. M.; COSTA, J. G. C.; ZWETKOFF, V. F., Confiabilidade de Redes de Transmissão e Subtransmissão Considerando Falhas em Equipamentos de Subestações: Uma Ferramenta para o Planejamento de Sistemas Elétricos. Anais do XXIV SNPTEE - Seminário Nacional de Produção e Transmissão de Energia Elétrica, artigo GPL29, Curitiba, PR, Brasil, 22-25 Outubro, 2017.

[49] NUNES, J. S.; LEITE DA SILVA, A. M.; COSTA, J. G. C., Impact of Transmission and Subtransmission Failures on Distribution Reliability Indices. Proceedings of the 15th PMAPS - Probabilistic Methods Applied to Power Systems, Boise, Idaho, USA, 24-28/June, paper 67, 2018.

[50] Department of Defense (DOD), Risk Management Guide for DOD Acquisition, Version 2.0, June 2003.

[51] ADREES, A.; MILANOVIC, J. V., Optimal compensation of transmission lines based on minimization of the risk of subsynchronous resonance, IEEE Trans. on Power Systems, vol. 31, nº 2, pp. 1038-1047, Mar. 2016.

[52] GIGUER, S., Proteção de Sistemas de Distribuição. $1^{a}$ Edição. Porto Alegre. Editora Sagra.

[53] MAMEDE FILHO, J., Manual de Equipamentos Elétricos. 3. Ed. Rio de Janeiro, LTC, 2005.

[54] ANEEL - Agência Nacional de Energia Elétrica, Resolução 024, Diário Oficial da União, Janeiro. 2000.

[55] PRODIST, Procedimentos de Distribuição de Energia Elétrica no Sistema Elétrico Nacional. Revisão 5, Módulo 8 - Qualidade da Energia Elétrica (Data de vigência: 01/01/2015), Agência Nacional de Energia Elétrica ANEEL, <Disponível em: http://www2.aneel.gov.br> acesso em Janeiro de 2018.

[56] BRAnCO FILHO, G., A Organização, o Planejamento e o Controle da Manutenção. Editora: Ciência Moderna, Rio de Janeiro, 2008.

[57] ALKAIM, J. L., Metodologia para incorporar conhecimento intensivo às tarefas de manutenção centrada na confiabilidade aplicada em ativos de sistemas elétricos. Tese Doutorado. Florianópolis, SC, Ed. UFSC, 2003.

[58] CAStella, M. C., Análise crítica da área de manutenção em uma empresa brasileira de geração de energia elétrica. Dissertação de Mestrado, Universidade Federal de Santa Catarina, Florianópolis, SC, 2001. 
[59] PATTON, Jr. Joseph D., Preventive Maintenance. Instrument Society of America, 1983.

[60] MOUBRAY, J., Reliability Centered Maintenance. 2nd. edition, New York: Industrial Press Inc., 1997.

[61] Ministério do Planejamento. <Disponível em: http://www.planejamento. gov.br/assuntos/gestao/controle-interno/matriz-de-riscos> Acesso em $26 / 01 / 2019$

[62] KARDEC, A.; NASCIF, J., Manutenção: Função Estratégica. Qualitymark, Rio de Janeiro, RJ, Brasil, 1998.

[63] FILHO, J. M., Instalações Elétricas Industriais. LTC, 8 a Edição, São Paulo, 2012.

[64] FILHO, J. M.; RIBEIRO, D. M., Proteção de Sistemas Elétricos de Potência. LTC, 2011.

[65] Sistema de Gestão da Distribuição. GDIS. <Disponível em: https://gdis/ > Acesso em Agosto, 2017.

[66] FERREIRA, M. I. J.; LEITE DA SILVA, A. M.; TAVARES, E., Maintenance Scheduling of Distribution Networks Based on Reliability Indices. VII Simpósio Brasileiro de Sistemas Elétricos (SBSE), Niterói, RJ, Brasil, 12-16 Maio, 2018. 


\section{Apêndice}

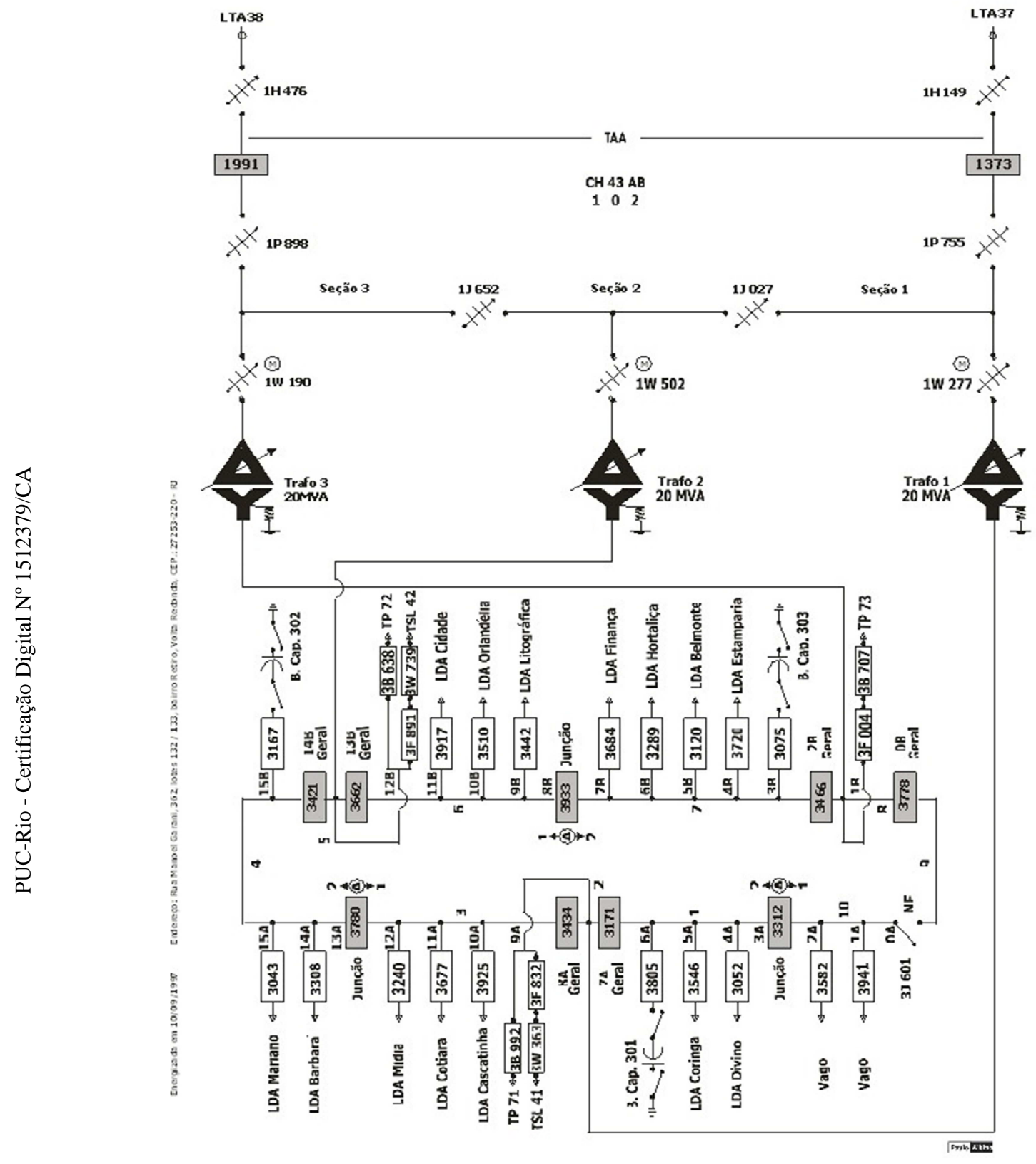

Figura 7.1 - Diagrama Original da SETD [65]. 


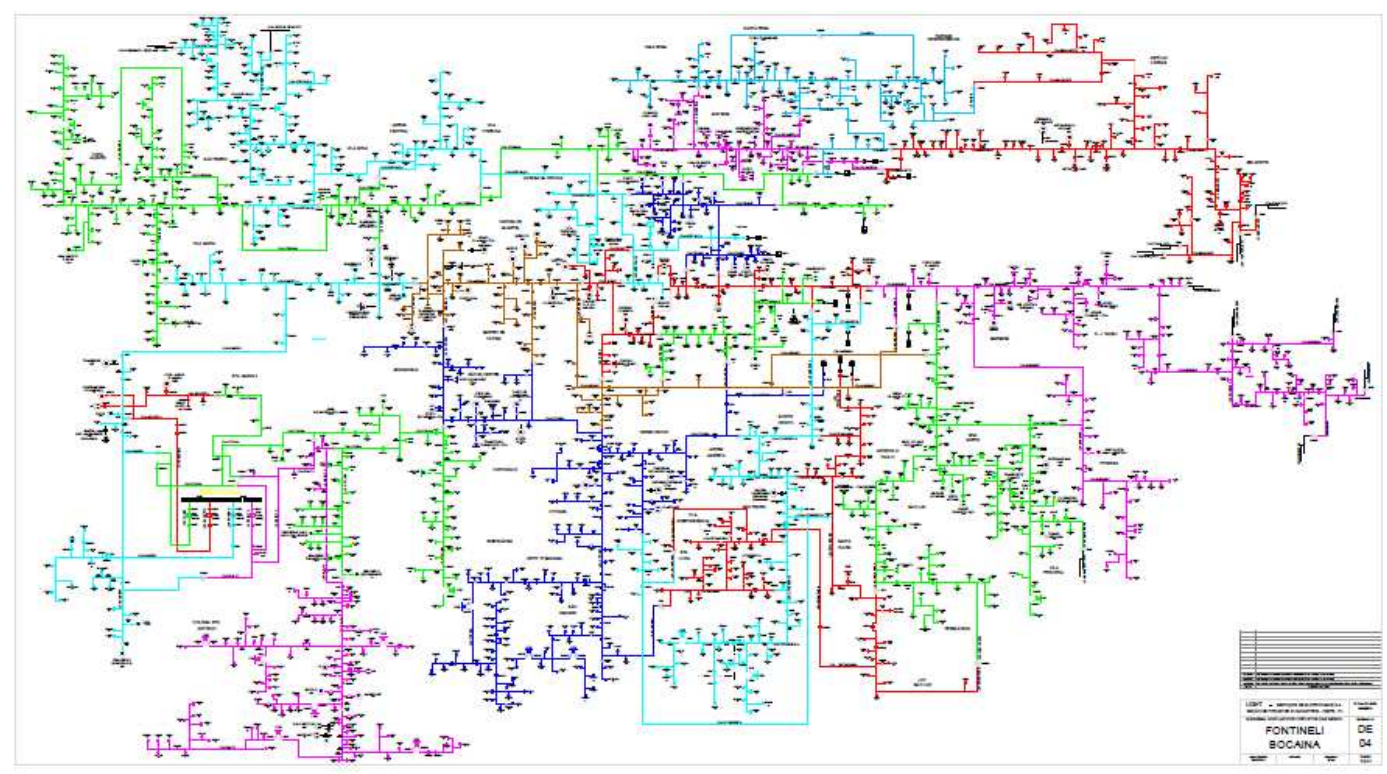

Figura 7.2 - Diagrama de distribuição [65]. 


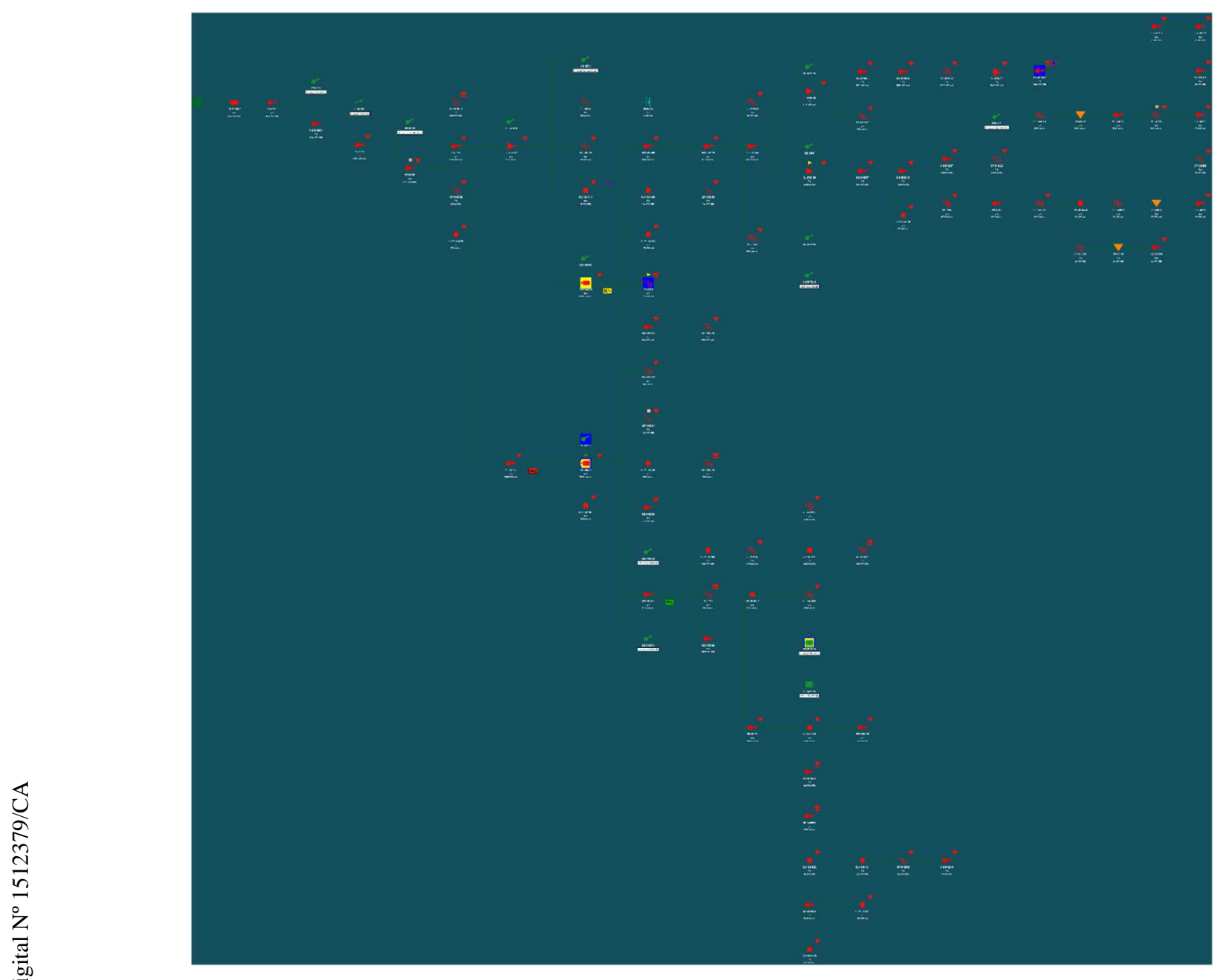

Figura 7.3 - LDA Cotiara: Visão Total [65].

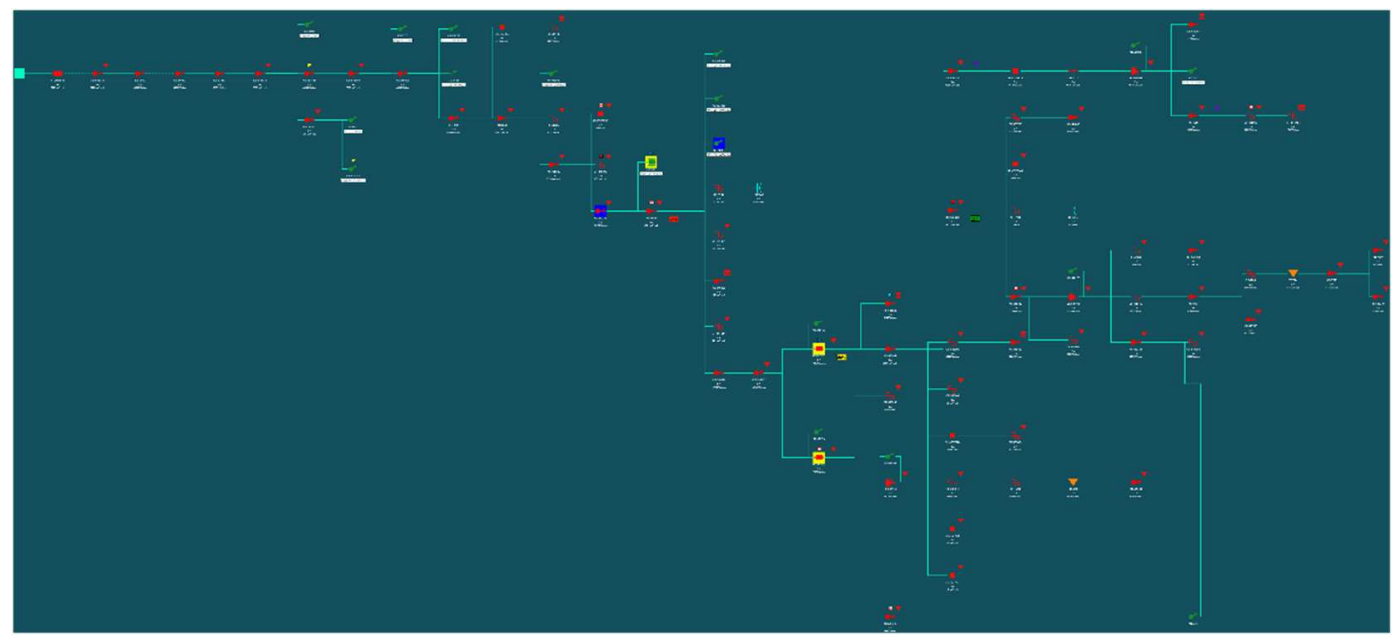

Figura 7.4 - LDA Coringa: Visão Total [65]. 